Article

\title{
Sustainability Psychology of Disruption: Attitude towards Water Purification Technology Can Be Predicted by Cultural Value Orientation and Personality Traits
}

\author{
Juneman Abraham ${ }^{1, *} \mathbb{\infty}$, Indhira Salsabilla ${ }^{1}\left(\mathbb{D}\right.$, Harco Leslie Hendric Spits Warnars ${ }^{2}{ }^{\circ}$, \\ Rudi Hartono Manurung ${ }^{3}\left[\right.$ and Yustinus Suhardi Ruman ${ }^{4}$ \\ 1 Psychology Department, Faculty of Humanities, Bina Nusantara University, DKI Jakarta 11480, Indonesia; \\ juneman@binus.ac.id (J.A.); salsabillaindhira@gmail.com (I.S.) \\ 2 Information System Concentration, Computer Science Department, Bina Nusantara University, \\ DKI Jakarta 11530, Indonesia; shendric@binus.edu \\ 3 Japanese Department, Faculty of Humanities, Bina Nusantara University, DKI Jakarta 11480, Indonesia; \\ rmanurung@binus.edu \\ 4 Communication Science Department \& Character Building Development Center, Bina Nusantara University, \\ DKI Jakarta 11480, Indonesia; yruman@binus.edu \\ * Correspondence: juneman@binus.ac.id; Tel.: +62-215345830
}

Citation: Abraham, J.; Salsabilla, I.; Warnars, H.L.H.S.; Manurung, R.H.; Ruman, Y.S. Sustainability Psychology of Disruption: Attitude towards Water Purification Technology Can Be Predicted by Cultural Value Orientation and Personality Traits. Sustainability 2021, 13, 12638. https://doi.org/10.3390/ su132212638

Academic Editor: María del C. Pérez-Fuentes

Received: 10 September 2021 Accepted: 9 November 2021 Published: 16 November 2021

Publisher's Note: MDPI stays neutral with regard to jurisdictional claims in published maps and institutional affiliations.

Copyright: (c) 2021 by the authors. Licensee MDPI, Basel, Switzerland. This article is an open access article distributed under the terms and conditions of the Creative Commons Attribution (CC BY) license (https:// creativecommons.org/licenses/by/ $4.0 /)$.

\begin{abstract}
The clean water crisis, particularly drinking water, is an issue that is strongly tied to water sustainability. The availability of disruptive technology that is cheaper and easy to use, such as a water purifier, is one answer to the ongoing crisis. Unfortunately, a disparity exists in the attitudes of Indonesia's society toward this technology. Five cultural orientations are set as predictors, each hypothesized as able to predict such attitudes as mediated by relevant personality traits. This study applied a correlational-predictive design toward 244 individuals (112 males and 132 females, $M_{\text {age }}=23.766$ years old, $S D_{\text {age }}=6.196$ years) residing in Jakarta, Indonesia's capital city. The main results were: (1) uncertainty avoidance can predict attitudes toward water purification technology through the conscientiousness trait; (2) power distance is unable to predict attitudes through neuroticism; (3) collectivism can predict attitudes through agreeableness; (4) masculinity is unable to predict attitudes through extraversion; and (5) long-term orientation can predict attitudes toward water purification technology through the openness trait. Prior studies have generally employed culture and personality as two separate predictors, yet this study might be the first in setting culture and personality as socio-psychological processes that shape a person's attitude toward water purification technology in a single theoretical model.
\end{abstract}

Keywords: cultural value; disruption; personality traits; sustainability psychology; water purification

\section{Introduction}

Earth's sustainability relies on the recycling of resources. One of the most substantial resource crises that humanity is currently facing is the global water crisis. Facts on water scarcity are published in the report of UN Water [1]. According to the report, water scarcity will be exacerbated as rapidly expanding urban areas put a strain on nearby water supplies. Climate change and bioenergy consumption are likely to inflame the current complex link between global development and water demand. One study that was cited by UN Water was a study by Burek et al. [2], stating that nearly half of the world's population presently spends at least one month each year in potentially water-scarce areas, and this number is expected to rise to $4.8-5.7$ billion by 2050 . Approximately $69-73$ percent of those affected live in Asia.

Indonesia is a region in Asia affected by safe water scarcity, and this present study will focus specifically on drinking water scarcity. One solution for drinking water scarcity, as suggested by Lisbona [3], is desalination of seawater, which typically contains high levels 
of fossil fuel pollutants. Technologies such as desalination are termed water purification technologies.

Rahman and Islam [4] summarized some such technologies, including biological wastewater, chemical precipitation, membrane separation (reverse osmosis, nano-filtration, ultrafiltration, and microfiltration), ion exchange technique, ozonation, and adsorption. These technologies have their own benefits and risks in addressing challenges within political, economic, social, cultural, defense and security, ecological, and corporatization domains [4].

In order to clarify the scope of this research, it is necessary to state the things that are covered and not covered by this research. This study covers an investigation of psychological predictors of the use of water purification technology. The psychological predictor in question is a person's intrapsychic dynamics which include the relation of cultural value orientation and personality traits. Meanwhile, this present study will not focus on solutions beyond mental and behavioral aspects of water purification, such as water quality protection, better water storage capacity, and demand management. This present study will also not focus on sustainability analysis on various water purification technologies. This study assumes that the need for water purification technology is obvious, which is to guarantee the fulfillment of human rights for safe drinking water, whatever the technology used might be [5]. In this regard, the use of water purification technology-whatever the technology may be-is considered pro-environmental behavior.

Although simpler water treatment methods exist, such as the boiling or chlorination that are mostly conducted in societies of developed countries, the availability of water disinfection/purification technologies is more cost-efficient, aside from its greater practicality [5].

Voutchkov [6] stated that water purification technologies are a disruption in a circular economy era. Voutchkov [6] mentioned two criteria for disruptive technology, being that (1) it is one-of-a-kind and (2) it is much more efficient (by at least $20 \%$ ) than the existing technology it replaces. Nonetheless, there are challenges to such disruptive technologies, such as how these technologies may yield (1) the development of new cost-effective and energy-efficient technologies; (2) new tools and methods for improved water quality and process performance monitoring; (3) enhancement of existing technologies' reliability, performance, flexibility, and robustness; and (4) advancement and implementation of "soft science" innovation to address the socioeconomic challenges of water reuse.

This study is an attempt to answer the fourth challenge. Psychology is considered a "soft science" [7] that is expected to play a role in answering social challenges toward environmental engagement. Arguably, environmental engagement is rooted in changing behavior and attitudes toward sustainable use of resources, and in this context, the use of purified water may partially answer the water crisis despite still sparking a certain level of controversy. The ongoing debates on the benefits and disadvantages of consuming purified water stem mostly from a health stance. Despite this, purified water is generally safe, as asserted by Kubala [8] (The Bottom Line section), "Purified water is relatively safe and may reduce exposure to certain contaminants that can be found in tap water".

Although drinking purified water is generally assumed to be safe and doing so ensures that the need to consume water that is vital and substantial is fulfilled, society is not always receptive to purified water (as part of recycled water). Fielding et al. [9] conducted a meta-synthesis on the acceptance of recycled water based on a search in Web of Science and PsycINFO. They discovered several factors associated with society's acceptance or rejection of this matter. Acceptance indicators, in this context, are the level of support, willingness or likelihood, happiness or comfortable feelings to use, positive attitudes, and satisfaction.

Although Fielding et al. [9] did not specifically study acceptance toward purified drinking water, the results are still relevant. They found the existence of a "pattern of lower acceptance for more personal uses" and that "There is a strong bias towards research in westernized nations" [9] (p. 3). 
Recycled water for drinking had the lowest acceptance rate compared to its use for plantation irrigation [9]. Furthermore, regarding demographic factors across various countries, age was shown to have different correlations toward acceptance. From a gender perspective, it was generally found that males are more accepting of recycled water as they showed more positive attitudes toward high-risk technology. Education level and income were also positively correlated with acceptance.

Psychological predictors such as disgust, health risk perception, general risk perception, distrust of authorities and science, perceived unfairness, and pricing concerns are negatively correlated with acceptance. Meanwhile, environmental concerns, supportive social norms, perceived benefits, knowledge, information, and prior experience were positively correlated with acceptance [9]. Still, regarding psychological factors, Lee et al. [10] found that the modified unified theory of acceptance and use of technology (UTAUT) model may account for a person's intent and behavior in using water purification technology. The modified UTAUT model comprises factors relating to physical support, educational support, performance expectancy, effort expectancy, facilitating condition, and role. As such, these models may help to better understand individual- and societal-level attitudes and behavior that may help inform scientists or policymakers in preservation issues. Aside from the demographic and psychological predictors stated above, Fielding [9] also examined the correlations between water characteristics with acceptance toward recycled water.

Based on Fielding's meta-synthesis [9], there were at least two issues that inspired or encouraged this study. Firstly, to address WEIRD (Western, Educated, Industrialized, Rich, Democratic) bias, studies in Indonesian samples as a representation of Eastern nations, as conducted in this present study, become highly relevant.

Secondly, quantitative studies that utilize personality predictors and cultural value orientation in an integrative model to account for attitudes toward purified water are yet available. Studies that investigate the role of both predictors separately are explained as follows. Regarding personality factors, Harmon et al. [11] discovered how personality traits, particularly in neuroticism and openness to experience, were able to predict acceptance of sustainable water alternatives, both in negative and positive directions.

Regarding cultural factors, Marks et al. [12] conducted a study toward urban Australian societies and found that diverse forms and uses of water have varied cultural meanings. Their finding is that public acceptance toward recycled water cannot be separated from cultural understandings or social construction of contamination, danger, cleanliness, and purity. Concerning purified water for drinking purposes, culture orients a person's body to set limitations on which substances may enter the body. Therefore, efforts to increase acceptance or positive attitudes toward purified water is not merely an issue of eliminating objective risks (microbes, bacteria, etc.) from water using technology but rather an issue of transforming cultural meanings about water, water sources, and water purification processes and technologies.

Because this present study places personality traits as a variable that can be shaped by cultural values, this study reinforces the constructivist or relativistic point of view about personality [13]. This perspective has a practical application, namely that to form a positive attitude towards water purification technology (which supports environmental sustainability), a community leader (or political leader) needs to obtain information about cultural situations from its members. Attitudes towards water purification technology are not merely a matter of an individual's personality, because in this present study, personality traits are a malleable—not stable—construct.

\subsection{Culture Is Mediated by Personality to Affect Attitude towards Water Purification Technology}

One relationship pattern that may exist between personality and culture is that the effect of culture toward a person is mediated by their personality, as asserted by Leong and Serafica [14] (p. 95), as follows: 
"In Holland's (1985) [15] view ... He sees culture influencing career development through its influence on personality development ... therefore, the effect of culture is mediated by personality types".

A similar statement was provided by Hofstede and McCrae [16] (p. 54, 71), as follows:

"The view that personality is created through the process of enculturation is akin to some contemporary ideas of psychological anthropology, which hold that culture is constitutive of personality (Miller, 1999) [17] ... Assuming that culture explains levels of trait scores rather than the other way round, Hofstede carried out a stepwise regression of the NEO-PI-R country means against the four IBM culture scores".

The statements demonstrate that studies on the predictive relationship between national cultures and personality traits have been conducted. Across 33 countries, it was found that (1) uncertainty avoidance and masculinity were predictors of neuroticism; (2) individualism and masculinity were predictors of extraversion; (3) uncertainty avoidance was a predictor of agreeableness; (4) power distance was a predictor of conscientiousness; and (5) masculinity, power distance, and uncertainty avoidance were predictors of openness to experience. Although these findings came from non-randomized controlled studies, it is worth noting that any data on personality and culture research in the context of environment-related attitudes is a useful knowledge to understand how culture influences the manifestation of traits for issues as critical as environmental engagement.

The difference between Hofstede and McCrae's [16] study with this present study is that the measurement of cultural orientation in this study uses Yoo et al.'s [18] measurement on the individual level. Aside from this, this present study aims to test a different hypothetical configuration compared to the associations mentioned in the above paragraphs and, simultaneously, attempts to correlate it with attitudes toward water purification technology.

In other words, this present study designates Big Five personality traits as mediators in the predictive relationships between cultural value orientations (at the individual level) and attitudes toward water purification technology. Specifically, the associations in the aforementioned hypothesis are as presented in Table 1.

Table 1. The five hypotheses of this present study.

\begin{tabular}{|c|c|c|c|}
\hline Hypothesis No. & $\begin{array}{l}\text { Predictor } \\
\text { (Cultural Value } \\
\text { Orientation) }\end{array}$ & $\begin{array}{l}\text { Mediator } \\
\text { (Personality Trait) }\end{array}$ & Criterion \\
\hline $\mathrm{H} 1$ & Uncertainty avoidance & Conscientiousness & $\begin{array}{l}\text { Attitude towards water } \\
\text { purification technology }\end{array}$ \\
\hline $\mathrm{H} 2$ & Power distance & Neuroticism & $\begin{array}{l}\text { Attitude towards water } \\
\text { purification technology }\end{array}$ \\
\hline H3 & Collectivism & Agreeableness & $\begin{array}{l}\text { Attitude towards water } \\
\text { purification technology }\end{array}$ \\
\hline $\mathrm{H} 4$ & Masculinity & Extraversion & $\begin{array}{l}\text { Attitude towards water } \\
\text { purification technology }\end{array}$ \\
\hline H5 & Long-term orientation & Openness & $\begin{array}{l}\text { Attitude towards water } \\
\text { purification technology }\end{array}$ \\
\hline
\end{tabular}

Attitude towards water purification technology is a summary appraisal of water purification technology along a dimension ranging from negative to positive. The attitude is hypothesized to be predicted by cultural value orientations mediated by personality traits.

Culture is the collective mental programming of the human mind that separates one group of people from another, as stated by Hofstede et al. [19]. This programming has an impact on thinking patterns, which are mirrored in the meaning people assign to many elements of life and become solidified in a society's institutions. The cultural aspects of Hofstede et al. [19] are universal values that influence all behavioral domains [18]. Chirkov et al. [20] showed that individuals absorb or internalize cultural orientations of 
the society to which they belong differently, depending on how those cultural orientations fulfill their basic psychological requirements. The descriptions of each cultural value orientation are listed below [18].

Uncertainty avoidance is a cultural value orientation that indicates an individual's anxiety level in the face of future uncertainty. The degree to which a member of society expects and accepts unequal power distribution is referred to as power distance. Collectivism describes a strong social structure in which individuals expect others in their group to support and protect them. A member of a culture with high masculinity is motivated by rivalry, achievement, assertiveness, and success. Long-term orientation is defined as to what degree a culture's member has a pragmatic future-oriented outlook as opposed to short-term traditional historical perspectives.

In this present study's context, personality traits are defined as "broad dimensions of individual differences between people, accounting for interindividual consistency and continuity in behavior, thought, and feeling across situations and overtime ... the overall style of a person's adjustment to and engagement of the social world", as stated by McAdams and Pals [21] (p. 207). The following are the descriptions of each personality trait according to John, Naumann, and Soto [22]. Self-discipline and a strong desire to complete duties are all characteristics of conscientiousness. Negative emotions (fear, sadness, anxiety, or disappointment), mental instability, inability to relax, frequent complaints, difficulty controlling oneself, and susceptibility to stress are all characteristics of neuroticism. Orientation toward other people and the community, humility toward other people, and trustworthiness are all characteristics of agreeableness. Extraversion is characterized by a strong interest in social situations, aggressiveness, firmness, and the capacity to gain energy from social interactions. Originality, depth, and breadth of knowledge, and a strong desire to create novel arrangements within one's life space describe openness to experience.

\subsection{Rationales of Hypotheses}

The rationale of the first hypothesis (H1): There have been indications that conscientiousness can positively predict attitudes toward water purification technology. Among others, conscientiousness is associated with a person with care and willingness traits to enhance their performance whereby new technologies may serve as a facilitator of that particular enhancement [23]. Aside from this, conscientiousness is associated with an environmentally conscious way of life [24], such as supporting water sustainability, as previously elaborated. Extraversion is also positively correlated with sustainable consumption [25]. Sustainable consumption in this context means [25] (p. 310):

"The search for ecologically-correct products and services, the preference for corporations and organizations actively engaged in environment conservation, the using of materials and equipment up to the end of its service life, the saving of resources such as water and energy, the reusing, whenever possible, the right destination of materials to recycling and the propensity to a lifestyle with less negative environment impact".

Conscientiousness might be predicted by uncertainty avoidance (UA). There is an indication that UA, as present in the GLOBE/Global Leadership and Organizational Behavior Effectiveness measurement, is positively correlated with conscientiousness [26]. Gründl and Aichholzer [27] explained that, although there is limited evidence, an indication was found that UA and conscientiousness have similar features, being the need for certainty or cognitive closure. The relationship between UA and conscientiousness has been empirically confirmed in a study by Berenbaum et al. [28]. They discovered a cognitive correlation between conscientiousness and three related uncertainty variables (uncertainty distress, uncertainty paralysis, and inflexible uncertainty beliefs). These three variables have opposing qualities with UA, whereas conscientiousness is positively correlated with the desire for predictability which is one of the main features of UA.

Based on the explanations above, this study hypothesized that uncertainty avoidance can positively predict favorable attitudes toward water purification technology through 
conscientiousness. Or, in other words, conscientiousness is a mediator between uncertainty avoidance and positive attitudes toward water purification technology (see H1 in Table 1).

The rationale of the second hypothesis (H2): There have been indications that neuroticism can negatively predict attitudes toward water purification technology. Among others, neuroticism is associated with anxiety, negative thoughts, low willingness to take risks despite potential gains, and fear of loss [29].

New technology generally contains elements of risks. Punnoose [29] elaborated on research findings that demonstrated how neuroticism is negatively correlated with the perceived usefulness of new technology. Technological development is perceived as threatening and suppressive. Aside from this, neuroticism is negatively correlated with a preference for recycled water [11]. Wester et al. [30] discovered that anticipated disgust is correlated with reluctance to use recycled water. Meanwhile, it was found that disgust is positively correlated with neuroticism [31].

Neuroticism might be predicted by power distance (PD). There is an indication that PD is positively correlated with neuroticism [32,33]. This positive correlation is very reasonable, as high power distance reflects a hierarchical, paternalistic, and autocratic culture whereby people in inferior positions must immediately accept the decisions of persons from higher ranks. Understandably, inequality and lack of democratization increase neuroticism [34,35]. Fatke [35] (p. 7) explained, "emotionally stable persons are less moved by the challenges social outcasts face in undemocratic systems". In other words, a positive reciprocal relationship between undemocratic situations and neuroticism exists (emotional instability, greater emotionality).

Based on the explanation above, this study hypothesized that power distance can negatively predict favorable attitudes toward water purification technology through neuroticism. Or, in other words, neuroticism is a mediator between power distance and negative attitudes toward water purification technology (see $\mathrm{H} 2$ in Table 1).

The rationale of the third hypothesis (H3): There have been indications that agreeableness can predict positive attitudes toward water purification technology. Among others, it was found that agreeableness (as characterized by cooperative, likable, kind, and helpful qualities) is positively correlated with technology acceptance, particularly in elements of perceived usefulness of that technology [36]. Maican et al. [37] explained that more agreeable individuals have higher effort expectancy, perceived ease of use, and hedonic incentive to use assistive technology. In addition, Hirsh [38] found that both on the individual or state level, agreeableness traits are positively correlated with environmental sustainability, particularly on water effects on the ecosystem as well as water effects on human health. Hirsh [38] further explained that individuals with higher agreeableness perceive their selves more as part of the larger community and even as part of nature. Due to this, such people are more empathic and have deep ecological concerns toward both the community's and nature's sustainability. The logical implication would be that water purification technology is viewed as a positive entity by people with high agreeableness.

Agreeableness might be predicted by collectivism. An empirical study by Burton et al. [39] confirmed that both vertical and horizontal collectivism is positively correlated with agreeableness. In one direction, agreeableness would predict collectivism, as suggested by Realo et al. [40] (p. 93), "Agreeable persons, who are also closed to experience, are comparatively more predisposed to absorb collectivistic elements from the culture into their own cognitive schemes". In addition, vice versa, as found by Javalagi and Newman [41], collectivism supports agreeableness. Triandis and Suh [42] explained how collectivism would predict agreeableness. They found that allocentrism-which has components of sociability, interdependence, and family integrity - is generally central in collectivist cultures. Meanwhile, allocentrism is positively correlated with agreeableness as allocentric individuals (1) have a greater tendency for affiliation, (2) have lower needs on individuality, (3) are more receptive of others, (4) prefer to adjust their needs with the needs of others (and tend to deny their personal needs and desires), and (5) are more sensitive 
toward social rejection. These five aspects are following the agreeableness personality trait features.

Based on the explanation above, this study hypothesized that collectivism can positively predict favorable attitudes toward water purification technology through agreeableness. Or, in other words, agreeableness is a mediator between collectivism and positive attitudes toward water purification technology (see H3 in Table 1).

The rationale of the fourth hypothesis (H4): There have been indications that extraversion can predict positive attitudes toward water purification technology. Among others, Behrenbruch et al. [43] found that extroverted individuals have higher levels of energy and readiness in dealing with doubts about technology. Extraverted individuals are also more likely to discern more benefits from technology when compared to introverted individuals who are more content with their lives. They tend to have greater intentions, compared to individuals with low extraversion, to use new technology [44]. Aside from this, Di Fabio and Rosen [45] found a positive correlation between extraversion and connectedness to nature. Wuertz [24] also discovered that extraversion is positively correlated with proenvironmental attitudes, including water conservation. In the context of this present study, water purification is part of water conservation [46].

Extraversion might be predicted by masculinity. Based on a review of numerous studies, Zheng and Zheng [47] concluded that masculinity, with its features of independence and self-reliance, contributes positively to extraversion, whether in Western or Eastern countries. Marušić and Bratko [48] argued that many prior studies have found a positive correlation between masculinity and other indicators of healthy psychological functioning (such as well-being, self-esteem, locus of control, depression) and that one indicator that has yet to be studied is extraversion (with qualities of warmth, positive emotionality, assertiveness, excitement-seeking, and gregariousness). In their empirical study in Croatia (a non-Western country), they found that masculinity does positively contribute to extraversion.

Based on the explanation above, this study hypothesized that masculinity can positively predict favorable attitudes toward water purification technology through extraversion. Or, in other words, extraversion is a mediator between masculinity and positive attitudes toward water purification technology (see H4 in Table 1).

The rationale of the fifth hypothesis (H5): There have been indications that openness can predict positive attitudes toward water purification technology. Among others, Behrenbruch et al. [43] found positive predictive correlations between openness and intention to use new technology. They argued that this may be due to openness traits that tend to seek new opportunities rather than familiarity. These individuals also provide more time to learn and reflect on new technology. Due to this, it is reasonable that openness is also correlated with perceived usefulness and perceived ease of use from new technology. Althuizen [49] corroborated that the novelty seeking and intellectual curiosity elements of the openness trait cause individuals with this trait to have attitudes, intentions, and behavior leaning toward trying newer and greater technology. A prior study by Harmon et al. [11] also found positive correlations between openness and attitudes toward water conservation. A study by Poškus [50] found that individuals with lower openness were incompatible with pro-environmental activities as such activities "require changing habits and adopting new practices" (p. 12).

Openness might be predicted by long-term orientation (LTO). Zotzmann et al. [51] and Krishnan [52], in an intercorrelation matrix between cultural values and personality dimensions, found a significant and positive correlation between LTO and openness. This is foreseeable as a long-term orientation has similar characteristics to openness, particularly the willingness to learn novel or unmastered things. As stated by Rüdian et al. [53] (p. 8), "Learners with high long-term orientation will spend longer periods of time in class preparing to successfully complete related exercises". Krishnan [52] added that the values possessed by people with higher LTO, being a preference towards future rewards, will cause them to (1) perceive technostress more positively, (2) be more willing to learn 
technology's complexity, and (3) share their knowledge. These three aspects are compatible with features of openness to new experiences.

Based on the explanations above, this study hypothesized that long-term orientation can positively predict favorable attitudes toward water purification technology through openness. Or, in other words, openness is a mediator between long-term orientation and positive attitudes toward water purification technology (see H5 in Table 1).

\section{Materials and Methods}

\subsection{Participants and Design}

This study's participants included 244 Indonesians residing in DKI Jakarta, the capital of Indonesia (112 males, 132 females; $M_{\text {age }}=23.766$ years old, $S D_{\text {age }}=6.196$ years $)$, recruited through convenience sampling.

With regard to ethnicities, the weighted sample was 30.3\% Javanese $(N=74), 14.3 \%$ Betawi $(N=35), 10.7 \%$ Sundanese $(N=26)$, and $11.5 \%$ Minangkabau $(N=28)$, while the remaining $13.1 \%$ identified as "Indonesian" $(N=32)$.

The majority of participants' education level was high school/equivalent (144 persons, $59 \%$ ), followed by Bachelor's (84 persons, 34.4\%), Diploma-3 (15 persons, 6.1\%), and elementary school (1 person, $0.4 \%$ ). Participants' occupations, however, were as follows: 127 persons were university students $(52 \%)$, 39 persons were private-sector employees (16\%), 25 persons were National Police members (10.2\%), 14 persons were medical students in internship year $(5.7 \%), 8$ persons were housewives $(3.3 \%), 8$ persons were in the private sector $(3.3 \%), 7$ persons were baristas $(2.9 \%), 6$ persons were entrepreneurs $(2.5 \%), 6$ persons were medical physicians $(2.5 \%), 2$ persons were consultants $(0.8 \%), 1$ person was a chef $(0.4 \%)$, and the 1 remaining participant was unemployed $(0.4 \%)$.

Based on monthly income, 84 persons had a monthly income of $<$ IDR 1,000,000 (34.4\%), 53 persons had income range IDR 1,000,000-IDR 2,500,000 (21.7\%), 54 persons had income range IDR 2,500,001-IDR 5,000,000 (22.1\%), 25 persons had income range IDR 5,000,001IDR 7,500,000 (10.2\%), 9 persons had income range IDR 7,500,001-IDR 10,000,000 (3.7\%), 7 persons had income range IDR 10,000,001-IDR 15,000,000 (2.9\%), and 12 persons had a monthly income of $>$ IDR 15,000,000 (4.9\%).

Based on water purification technology use status, 52 persons (21.3\%) were currently using such technology, 67 persons $(27.5 \%)$ have ever used such technology, and 125 persons $(51.2 \%)$ have never used such technology. This shows that this study has a variety of subject experiences with a fairly balanced composition.

This study applies a predictive correlational design. As shown in Table 1, the predictor variables in this study are cultural value orientations on the individual level, whereas the criterion variable is attitudes toward water purification technology. The predictive relationship between the predictor and criterion variable in this study is hypothesized to be mediated by personality traits.

\subsection{Materials, Instruments, and Data Analysis}

Data were retrieved using an online Indonesian questionnaire. The questionnaire was divided into several parts, with the following order: (1) cover letter, (2) instructions, (3) personality trait scale, (4) cultural value orientation scale, (5) attitude toward water purification scale, and (6) participant demographic data.

In the cover letter section, the authors introduced themselves and the study's objectives. In addition, the authors provide an informed consent form to be filled by participants who were willing to participate in the study. This study was initially permitted to be conducted by the Indonesian Ministry of Education and Culture, as stated in the Director of Research and Community Service Letter No: B/112/E3/RA.00/2021, regarding the Announcement of Research Funding Beneficiaries in Indonesian Higher Education, and further declared in the Region III Higher Education Service Board Letter (LLDikti III) along with the Letter of the Head of LLDikti III No. 705/LL3/KR/2021, for the study entitled, 
"Exploring the Contribution of Personality and Societal Cultural Orientation in Explaining Attitudes Toward Disruptive Changes".

In the instructions section, the authors provided an imaginative scenario, as follows:

"In the process of completing this questionnaire, you will be asked to imagine the following situation as if it were truly happening.

There is a water crisis in your area whereby all water sources are contaminated by substances that cause the water to be unsafe for consumption (drinking). The only way to retrieve clean water is by using water purification technology in which such technology is affordable and maintained easily.

There are a few alternatives in how the water purification technology works, such as (1) carbon filter, (2) bio-sand filter, (3) reverse osmosis filters, (4) ultraviolet (UV) filter, (5) ceramic filter, and (6) ion-exchange filter). (Note: the authors briefly explained the mechanisms of each of these six methods).

Please respond to the following statements in the following sections according to the previously imagined situation."

The personality traits scale (conscientiousness, neuroticism, agreeableness, extraversion, and openness) was adopted from the Indonesian version of the Big Five Personality Scale, as adapted by Ramdhani [54]. This scale begins with the following statement, "I see myself as someone who ..." ". This scale consists of 44 items that describe a person's personality traits and facets, such as being easily upset, often generates new ideas, has an active imagination, and others. This scale comprises the following composition: 9 conscientiousness items (Cronbach's Alpha $=0.777), 8$ neuroticism items (Cronbach's Alpha $=0.828), 9$ agreeableness items (Cronbach's Alpha $=0.668), 8$ extraversion items (Cronbach's Alpha $=0.748)$, and 10 openness items (Cronbach's Alpha $=0.613)$. The complete list of items in this scale is available in Ramdhani's [54] publication. This scale's answers range from Strongly Disagree (scored 1) to Strongly Agree (Scored 5). The average number of each variable is used to determine how high or how low the ownership of the attribute being measured is. The average number is used, not the total score, because it is considered more meaningful in its interpretation, although the statistical results in the form of standardized results between the average and total score are identical [55].

The construct validities of each scale of personality traits were proved by confirmatory factor analyses (CFA), as shown in Tables 2-6 (all related figures can be found at https:/ / doi.org/10.5281/zenodo.5606479 (accessed on 9 September 2021), in worksheet CFA-Instrument Validation). Special note on the Openness scale; because items O7 (Estimate $=-0.039, p=0.624)$ and O9 (Estimate $=-0.063, p=0.377)$ (see Table 6) showed insignificant estimates $(p>0.05)$, then in further calculations, these two items are not taken into account in determining the Openness (Changed Cronbach's Alpha $=0.704$ ) average score.

To test the hypotheses $\mathrm{H} 1$ to $\mathrm{H} 5$, this study applies mediation analysis (standardized estimates presented) utilizing JASP (Jeffrey's Amazing Statistics Program) version 0.11.1 for Windows.

Table 2. Item loadings of confirmatory factor analysis of conscientiousness $(n=9, N=244)$.

\begin{tabular}{|c|c|c|c|c|c|c|c|c|c|}
\hline \multirow[b]{2}{*}{ Factor } & \multirow[b]{2}{*}{ Indicator } & \multirow[b]{2}{*}{ Symbol } & \multirow[b]{2}{*}{ Estimate } & \multirow[b]{2}{*}{ Std. Error } & \multirow[b]{2}{*}{$z$} & \multicolumn{4}{|c|}{ 95\% Confidence Interval } \\
\hline & & & & & & $p$ & Lower & Upper & Std. Est. (All) \\
\hline \multirow[t]{9}{*}{$\mathrm{C}$} & $\mathrm{C} 1$ & $\lambda 11$ & 0.531 & 0.057 & 9.308 & 0.000 & 0.419 & 0.643 & 0.602 \\
\hline & $\mathrm{C} 2$ & $\lambda 12$ & 0.461 & 0.060 & 7.680 & $1.599 \times 10^{-14}$ & 0.344 & 0.579 & 0.512 \\
\hline & C3 & $\lambda 13$ & 0.503 & 0.052 & 9.634 & 0.000 & 0.401 & 0.605 & 0.620 \\
\hline & $\mathrm{C} 4$ & $\lambda 14$ & 0.417 & 0.051 & 8.196 & $2.220 \times 10^{-16}$ & 0.317 & 0.516 & 0.541 \\
\hline & C5 & $\lambda 15$ & 0.390 & 0.057 & 6.810 & $9.732 \times 10^{-12}$ & 0.278 & 0.502 & 0.460 \\
\hline & C6 & $\lambda 16$ & 0.555 & 0.075 & 7.376 & $1.636 \times 10^{-13}$ & 0.407 & 0.702 & 0.494 \\
\hline & C7 & $\lambda 17$ & 0.493 & 0.084 & 5.893 & $3.787 \times 10^{-9}$ & 0.329 & 0.657 & 0.404 \\
\hline & $\mathrm{C} 8$ & $\lambda 18$ & 0.739 & 0.068 & 10.849 & 0.000 & 0.606 & 0.873 & 0.682 \\
\hline & C9 & $\lambda 19$ & 0.596 & 0.074 & 8.000 & $1.332 \times 10^{-15}$ & 0.450 & 0.741 & 0.530 \\
\hline
\end{tabular}


Table 3. Item loadings of confirmatory factor analysis of neuroticism $(n=8, N=244)$.

\begin{tabular}{|c|c|c|c|c|c|c|c|c|c|}
\hline \multirow[b]{2}{*}{ Factor } & \multirow[b]{2}{*}{ Indicator } & \multirow[b]{2}{*}{ Symbol } & \multirow[b]{2}{*}{ Estimate } & \multirow[b]{2}{*}{ Std. Error } & \multirow[b]{2}{*}{$z$} & \multicolumn{3}{|c|}{ 95\% Confidence Interval } & \multirow[b]{2}{*}{ Std. Est. (All) } \\
\hline & & & & & & $p$ & Lower & Upper & \\
\hline \multirow[t]{8}{*}{$\mathrm{N}$} & N1 & $\lambda 11$ & 0.673 & 0.072 & 9.335 & 0.000 & 0.532 & 0.815 & 0.593 \\
\hline & N2 & $\lambda 12$ & 0.704 & 0.067 & 10.429 & 0.000 & 0.571 & 0.836 & 0.648 \\
\hline & N3 & $\lambda 13$ & 0.725 & 0.071 & 10.220 & 0.000 & 0.586 & 0.864 & 0.638 \\
\hline & N4 & $\lambda 14$ & 0.693 & 0.072 & 9.647 & 0.000 & 0.552 & 0.833 & 0.609 \\
\hline & N5 & $\lambda 15$ & 0.744 & 0.069 & 10.844 & 0.000 & 0.609 & 0.878 & 0.669 \\
\hline & N6 & $\lambda 16$ & 0.617 & 0.066 & 9.333 & 0.000 & 0.487 & 0.746 & 0.593 \\
\hline & N7 & $\lambda 17$ & 0.567 & 0.062 & 9.141 & 0.000 & 0.446 & 0.689 & 0.583 \\
\hline & N8 & $\lambda 18$ & 0.555 & 0.062 & 9.019 & 0.000 & 0.435 & 0.676 & 0.576 \\
\hline
\end{tabular}

Note. $\mathrm{N}=$ neuroticism.

Table 4. Item loadings of confirmatory factor analysis of agreeableness $(n=9, N=244)$.

\begin{tabular}{|c|c|c|c|c|c|c|c|c|c|}
\hline \multirow[b]{2}{*}{ Factor } & \multirow[b]{2}{*}{ Indicator } & \multirow[b]{2}{*}{ Symbol } & \multirow[b]{2}{*}{ Estimate } & \multirow[b]{2}{*}{ Std. Error } & \multirow[b]{2}{*}{$z$} & \multicolumn{4}{|c|}{ 95\% Confidence Interval } \\
\hline & & & & & & $p$ & Lower & Upper & Std. Est. (All) \\
\hline \multirow[t]{9}{*}{ A } & A1 & $\lambda 11$ & 0.210 & 0.081 & 2.587 & 0.010 & 0.051 & 0.369 & 0.194 \\
\hline & $\mathrm{A} 2$ & $\lambda 12$ & 0.578 & 0.064 & 8.972 & 0.000 & 0.452 & 0.704 & 0.630 \\
\hline & A3 & $\lambda 13$ & 0.333 & 0.053 & 6.257 & $3.919 \times 10^{-10}$ & 0.229 & 0.438 & 0.453 \\
\hline & $\mathrm{A} 4$ & $\lambda 14$ & 0.446 & 0.062 & 7.141 & $9.259 \times 10^{-13}$ & 0.323 & 0.568 & 0.512 \\
\hline & A5 & $\lambda 15$ & 0.343 & 0.063 & 5.428 & $5.708 \times 10^{-8}$ & 0.219 & 0.467 & 0.397 \\
\hline & A6 & $\lambda 16$ & 0.546 & 0.085 & 6.461 & $1.040 \times 10^{-10}$ & 0.381 & 0.712 & 0.467 \\
\hline & A7 & $\lambda 17$ & 0.499 & 0.073 & 6.849 & $7.440 \times 10^{-12}$ & 0.356 & 0.642 & 0.493 \\
\hline & A8 & $\lambda 18$ & 0.464 & 0.075 & 6.146 & $7.929 \times 10^{-10}$ & 0.316 & 0.612 & 0.446 \\
\hline & A9 & $\lambda 19$ & 0.388 & 0.084 & 4.604 & $4.142 \times 10^{-6}$ & 0.223 & 0.553 & 0.340 \\
\hline
\end{tabular}

Note. $\mathrm{A}=$ agreeableness.

Table 5. Item loadings of confirmatory factor analysis of extraversion $(n=8, N=244)$.

\begin{tabular}{|c|c|c|c|c|c|c|c|c|c|}
\hline \multirow[b]{2}{*}{ Factor } & \multirow[b]{2}{*}{ Indicator } & \multirow[b]{2}{*}{ Symbol } & \multirow[b]{2}{*}{ Estimate } & \multirow[b]{2}{*}{ Std. Error } & \multirow[b]{2}{*}{$z$} & \multicolumn{4}{|c|}{ 95\% Confidence Interval } \\
\hline & & & & & & $p$ & Lower & Upper & Std. Est. (All) \\
\hline \multirow[t]{8}{*}{$\mathrm{E}$} & E1 & $\lambda 11$ & 0.526 & 0.066 & 8.004 & $1.110 \times 10^{-15}$ & 0.398 & 0.655 & 0.536 \\
\hline & E2 & $\lambda 12$ & 0.479 & 0.058 & 8.223 & $2.220 \times 10^{-16}$ & 0.365 & 0.593 & 0.549 \\
\hline & E3 & $\lambda 13$ & 0.479 & 0.060 & 8.039 & $8.882 \times 10^{-16}$ & 0.363 & 0.596 & 0.538 \\
\hline & E4 & $\lambda 14$ & 0.222 & 0.071 & 3.104 & 0.002 & 0.082 & 0.362 & 0.222 \\
\hline & E5 & $\lambda 15$ & 0.577 & 0.056 & 10.235 & 0.000 & 0.467 & 0.688 & 0.660 \\
\hline & E6 & $\lambda 16$ & 0.789 & 0.081 & 9.790 & 0.000 & 0.631 & 0.947 & 0.636 \\
\hline & E7 & $\lambda 17$ & 0.687 & 0.075 & 9.142 & 0.000 & 0.539 & 0.834 & 0.601 \\
\hline & E8 & $\lambda 18$ & 0.534 & 0.077 & 6.947 & $3.743 \times 10^{-12}$ & 0.383 & 0.685 & 0.474 \\
\hline
\end{tabular}

Note. E = extraversion.

Table 6. Item loadings of confirmatory factor analysis of openness $(n=10, N=244)$.

\begin{tabular}{|c|c|c|c|c|c|c|c|c|c|}
\hline \multirow[b]{2}{*}{ Factor } & \multirow[b]{2}{*}{ Indicator } & \multirow[b]{2}{*}{ Symbol } & \multirow[b]{2}{*}{ Estimate } & \multirow[b]{2}{*}{ Std. Error } & \multirow[b]{2}{*}{$z$} & \multicolumn{4}{|c|}{ 95\% Confidence Interval } \\
\hline & & & & & & $p$ & Lower & Upper & Std. Est. (All) \\
\hline \multirow[t]{10}{*}{$\mathrm{O}$} & $\mathrm{O} 1$ & $\lambda 11$ & 0.454 & 0.061 & 7.435 & $1.048 \times 10^{-13}$ & 0.335 & 0.574 & 0.518 \\
\hline & $\mathrm{O} 2$ & $\lambda 12$ & 0.393 & 0.061 & 6.473 & $9.611 \times 10^{-11}$ & 0.274 & 0.512 & 0.457 \\
\hline & $\mathrm{O} 3$ & $\lambda 13$ & 0.449 & 0.054 & 8.292 & $2.220 \times 10^{-16}$ & 0.343 & 0.555 & 0.571 \\
\hline & $\mathrm{O} 4$ & $\lambda 14$ & 0.499 & 0.064 & 7.810 & $5.773 \times 10^{-15}$ & 0.374 & 0.624 & 0.541 \\
\hline & O5 & $\lambda 15$ & 0.503 & 0.056 & 8.948 & 0.000 & 0.393 & 0.613 & 0.610 \\
\hline & O6 & $\lambda 16$ & 0.482 & 0.061 & 7.938 & $1.998 \times 10^{-15}$ & 0.363 & 0.601 & 0.549 \\
\hline & O7 & $\lambda 17$ & -0.039 & 0.080 & -0.490 & 0.624 & -0.195 & 0.117 & -0.036 \\
\hline & O8 & $\lambda 18$ & 0.509 & 0.082 & 6.228 & $4.733 \times 10^{-10}$ & 0.349 & 0.670 & 0.442 \\
\hline & O9 & $\lambda 19$ & -0.063 & 0.071 & -0.884 & 0.377 & -0.203 & 0.077 & -0.066 \\
\hline & $\mathrm{O} 10$ & $\lambda 110$ & 0.290 & 0.086 & 3.377 & $7.340 \times 10^{-4}$ & 0.122 & 0.458 & 0.247 \\
\hline
\end{tabular}

Note. $\mathrm{O}=$ openness.

The cultural value orientation scale (uncertainty avoidance, power distance, collectivism, masculinity, and long-term orientation) is adapted from the Scale of Individual Cultural Values (CVSCALE; Yoo et al.) [18]. CVSCALE is made up of five dimensions of cultural values as defined by Hofstede et al. [19]; however, it was measured on an 
individual—not country-basis. This scale comprises 24 items that present a person's cultural orientation. Its composition is as follows: 5 uncertainty avoidance items (Cronbach's Alpha $=0.796), 5$ power distance items (Cronbach's Alpha $=0.776), 6$ collectivism items (Cronbach's Alpha $=0.684), 4$ masculinity items (Cronbach's Alpha $=0.726)$, and 4 long-term orientation items (Cronbach's Alpha $=0.684$ ). The complete item list of this scale is available in Yoo et al.'s [18] publication. This scale's answers range from Strongly Disagree (scored 1) to Strongly Agree (Scored 5). The construct validities of each scale of cultural value orientation were proved by confirmatory factor analyses (CFA), as shown in Tables 7-11 (All related figures can be found at https:/ / doi.org/10.5281/zenodo.5606479 (accessed on 9 September 2021), in worksheet CFA-Instrument Validation).

Table 7. Item loadings of confirmatory factor analysis of uncertainty avoidance $(n=5, N=244)$.

\begin{tabular}{|c|c|c|c|c|c|c|c|c|c|}
\hline \multirow[b]{2}{*}{ Factor } & \multirow[b]{2}{*}{ Indicator } & \multirow[b]{2}{*}{ Symbol } & \multirow[b]{2}{*}{ Estimate } & \multirow[b]{2}{*}{ Std. Error } & \multicolumn{5}{|c|}{ 95\% Confidence Interval } \\
\hline & & & & & $z$ & $p$ & Lower & Upper & Std. Est. (All) \\
\hline \multirow[t]{5}{*}{ UA } & UA1 & $\lambda 11$ & 0.469 & 0.056 & 8.313 & 0.000 & 0.358 & 0.580 & 0.545 \\
\hline & UA2 & $\lambda 12$ & 0.555 & 0.047 & 11.689 & 0.000 & 0.462 & 0.648 & 0.721 \\
\hline & UA3 & $\lambda 13$ & 0.587 & 0.051 & 11.604 & 0.000 & 0.488 & 0.686 & 0.717 \\
\hline & UA4 & $\lambda 14$ & 0.471 & 0.045 & 10.563 & 0.000 & 0.384 & 0.558 & 0.665 \\
\hline & UA5 & $\lambda 15$ & 0.517 & 0.047 & 11.057 & 0.000 & 0.425 & 0.609 & 0.689 \\
\hline
\end{tabular}

Note. UA = uncertainty avoidance.

Table 8. Item loadings of confirmatory factor analysis of power distance $(n=5, N=244)$.

\begin{tabular}{|c|c|c|c|c|c|c|c|c|c|}
\hline \multirow[b]{2}{*}{ Factor } & \multirow[b]{2}{*}{ Indicator } & \multirow[b]{2}{*}{ Symbol } & \multirow[b]{2}{*}{ Estimate } & \multirow[b]{2}{*}{ Std. Error } & \multirow[b]{2}{*}{$z$} & \multicolumn{4}{|c|}{ 95\% Confidence Interval } \\
\hline & & & & & & $p$ & Lower & Upper & Std. Est. (All) \\
\hline \multirow[t]{5}{*}{$\mathrm{PD}$} & PD1 & $\lambda 11$ & 0.796 & 0.071 & 11.249 & 0.000 & 0.658 & 0.935 & 0.710 \\
\hline & PD2 & $\lambda 12$ & 0.689 & 0.069 & 9.926 & 0.000 & 0.553 & 0.826 & 0.640 \\
\hline & PD3 & $\lambda 13$ & 0.725 & 0.064 & 11.374 & 0.000 & 0.600 & 0.850 & 0.717 \\
\hline & PD4 & $\lambda 14$ & 0.659 & 0.070 & 9.471 & 0.000 & 0.522 & 0.795 & 0.616 \\
\hline & PD5 & $\lambda 15$ & 0.637 & 0.079 & 8.086 & $6.661 \times 10^{-16}$ & 0.483 & 0.791 & 0.539 \\
\hline
\end{tabular}

Note. $\mathrm{PD}=$ power distance.

Table 9. Item loadings of confirmatory factor analysis of collectivism $(n=6, N=244)$.

\begin{tabular}{|c|c|c|c|c|c|c|c|c|c|}
\hline \multirow[b]{2}{*}{ Factor } & \multirow[b]{2}{*}{ Indicator } & \multirow[b]{2}{*}{ Symbol } & \multirow[b]{2}{*}{ Estimate } & \multirow[b]{2}{*}{ Std. Error } & \multirow[b]{2}{*}{$z$} & \multicolumn{4}{|c|}{ 95\% Confidence Interval } \\
\hline & & & & & & $p$ & Lower & Upper & Std. Est. (All) \\
\hline \multirow[t]{6}{*}{ COL } & COL1 & $\lambda 11$ & 0.515 & 0.062 & 8.345 & 0.000 & 0.394 & 0.636 & 0.542 \\
\hline & COL2 & $\lambda 12$ & 0.454 & 0.063 & 7.223 & $5.094 \times 10^{-13}$ & 0.331 & 0.578 & 0.477 \\
\hline & COL3 & $\lambda 13$ & 0.810 & 0.058 & 13.908 & 0.000 & 0.696 & 0.924 & 0.838 \\
\hline & COL4 & $\lambda 14$ & 0.742 & 0.058 & 12.770 & 0.000 & 0.628 & 0.856 & 0.780 \\
\hline & COL5 & $\lambda 15$ & 0.041 & 0.076 & 0.537 & 0.591 & -0.108 & 0.189 & 0.038 \\
\hline & COL6 & $\lambda 16$ & 0.415 & 0.064 & 6.503 & $7.860 \times 10^{-11}$ & 0.290 & 0.540 & 0.435 \\
\hline
\end{tabular}

Note. $\mathrm{COL}=$ collectivism.

Table 10. Item loadings of confirmatory factor analysis of masculinity $(n=4, N=244)$.

\begin{tabular}{|c|c|c|c|c|c|c|c|c|c|}
\hline \multirow[b]{2}{*}{ Factor } & \multirow[b]{2}{*}{ Indicator } & \multirow[b]{2}{*}{ Symbol } & \multirow[b]{2}{*}{ Estimate } & \multirow[b]{2}{*}{ Std. Error } & \multirow[b]{2}{*}{$z$} & \multicolumn{4}{|c|}{ 95\% Confidence Interval } \\
\hline & & & & & & $p$ & Lower & Upper & Std. Est. (All) \\
\hline \multirow{4}{*}{ MAS } & MAS1 & $\lambda 11$ & 0.835 & 0.086 & 9.753 & 0.000 & 0.667 & 1.002 & 0.636 \\
\hline & MAS2 & $\lambda 12$ & 0.751 & 0.069 & 10.904 & 0.000 & 0.616 & 0.886 & 0.706 \\
\hline & MAS3 & $\lambda 13$ & 0.844 & 0.067 & 12.642 & 0.000 & 0.713 & 0.975 & 0.814 \\
\hline & MAS4 & $\lambda 14$ & 0.478 & 0.076 & 6.253 & $4.026 \times 10^{-10}$ & 0.328 & 0.628 & 0.429 \\
\hline
\end{tabular}


Table 11. Item loadings of confirmatory factor analysis of long-term orientation $(n=4, N=244)$.

\begin{tabular}{|c|c|c|c|c|c|c|c|c|c|}
\hline \multirow[b]{2}{*}{ Factor } & \multirow[b]{2}{*}{ Indicator } & \multirow[b]{2}{*}{ Symbol } & \multirow[b]{2}{*}{ Estimate } & \multirow[b]{2}{*}{ Std. Error } & \multirow[b]{2}{*}{$z$} & \multicolumn{4}{|c|}{ 95\% Confidence Interval } \\
\hline & & & & & & $p$ & Lower & Upper & Std. Est. (All) \\
\hline \multirow[t]{4}{*}{ LTO } & LTO1 & $\lambda 11$ & 0.403 & 0.045 & 9.007 & 0.000 & 0.316 & 0.491 & 0.611 \\
\hline & LTO2 & $\lambda 12$ & 0.573 & 0.053 & 10.730 & 0.000 & 0.469 & 0.678 & 0.729 \\
\hline & LTO3 & $\lambda 13$ & 0.405 & 0.069 & 5.866 & $4.453 \times 10^{-9}$ & 0.270 & 0.541 & 0.415 \\
\hline & LTO4 & $\lambda 14$ & 0.499 & 0.047 & 10.709 & 0.000 & 0.407 & 0.590 & 0.727 \\
\hline
\end{tabular}

Note. $\mathrm{LTO}=$ long-term orientation

The attitude toward water purification technology scale was constructed by the authors by adapting Krosnick et al.'s [56] attitude dimensions, (1) direct experience (2 items), (2) knowledge (2 items), (3) extremity/intensity (8 items), (4) affective-cognitive consistency ( 2 items), (5) certainty ( 3 items), (6) importance (3 items), (7) interest in relevant information ( 2 items), and ( 8 ) accessibility (4 items). This scale consists of 26 items, with water purification technology as an attitude object. The examples of each of the dimensions are: (1) "I have good experience in using water purification technology (WPT)", (2) "I know how WPT works", (3) "I completely accept WPT", (4) "I feel unhappy about WPT as I do not trust such technology" (unfavorable item, reversely coded), (5) "I am assured of WPT", (6) "WPT is important for me", (7) "I always seek information on WPT", and (8) "Now I often talk about WPT with my surroundings". This scale's answers range from Strongly Disagree (scored 1) to Strongly Agree (scored 5). This scale is deemed reliable with Cronbach's Alpha $=0.906$. The construct validity of the attitude scale was proved by confirmatory factor analyses (CFA), as shown in Table 12.

Table 12. Item loadings of confirmatory factor analysis of attitude towards water purification technology $(n=26, N=244)$.

\begin{tabular}{|c|c|c|c|c|c|c|c|c|c|}
\hline \multirow[b]{2}{*}{ Factor } & \multirow[b]{2}{*}{ Indicator } & \multirow[b]{2}{*}{ Symbol } & \multirow[b]{2}{*}{ Estimate } & \multirow[b]{2}{*}{ Std. Error } & \multirow[b]{2}{*}{$z$} & \multicolumn{4}{|c|}{ 95\% Confidence Interval } \\
\hline & & & & & & $p$ & Lower & Upper & Std. Est. (All) \\
\hline \multirow[t]{2}{*}{ DIR } & DIR1 & $\lambda 11$ & 0.999 & 0.080 & 12.407 & 0.000 & 0.841 & 1.156 & 0.787 \\
\hline & DIR2 & $\lambda 12$ & 1.009 & 0.073 & 13.817 & 0.000 & 0.866 & 1.153 & 0.874 \\
\hline \multirow[t]{2}{*}{ KNO } & KNO1 & $\lambda 21$ & 0.902 & 0.077 & 11.659 & 0.000 & 0.751 & 1.054 & 0.795 \\
\hline & KNO2 & $\lambda 22$ & 0.729 & 0.074 & 9.908 & 0.000 & 0.585 & 0.873 & 0.663 \\
\hline \multirow[t]{8}{*}{ EXT } & EXT1 & $\lambda 31$ & 0.718 & 0.052 & 13.723 & 0.000 & 0.616 & 0.821 & 0.763 \\
\hline & EXT2 & $\lambda 32$ & 0.674 & 0.049 & 13.670 & 0.000 & 0.577 & 0.770 & 0.761 \\
\hline & ЕХT3 & $\lambda 33$ & 0.632 & 0.059 & 10.656 & 0.000 & 0.516 & 0.748 & 0.632 \\
\hline & EXT4 & $\lambda 34$ & 0.609 & 0.055 & 11.067 & 0.000 & 0.501 & 0.716 & 0.651 \\
\hline & EXT5 & $\lambda 35$ & 0.703 & 0.058 & 12.193 & 0.000 & 0.590 & 0.817 & 0.701 \\
\hline & EXT6 & $\lambda 36$ & 0.556 & 0.059 & 9.468 & 0.000 & 0.441 & 0.671 & 0.574 \\
\hline & EXT7 & $\lambda 37$ & 0.557 & 0.061 & 9.054 & 0.000 & 0.436 & 0.677 & 0.553 \\
\hline & EXT8 & $\lambda 38$ & 0.528 & 0.051 & 10.360 & 0.000 & 0.428 & 0.628 & 0.618 \\
\hline \multirow[t]{2}{*}{ AFC } & AFC1 & $\lambda 41$ & 0.386 & 0.068 & 5.677 & $1.373 \times 10^{-8}$ & 0.253 & 0.520 & 0.386 \\
\hline & AFC2 & $\lambda 42$ & 0.776 & 0.075 & 10.340 & 0.000 & 0.629 & 0.923 & 0.834 \\
\hline \multirow[t]{3}{*}{ CER } & CER1 & $\lambda 51$ & 0.642 & 0.055 & 11.693 & 0.000 & 0.534 & 0.749 & 0.684 \\
\hline & CER2 & $\lambda 52$ & 0.699 & 0.053 & 13.192 & 0.000 & 0.595 & 0.803 & 0.749 \\
\hline & CER3 & $\lambda 53$ & 0.737 & 0.052 & 14.258 & 0.000 & 0.635 & 0.838 & 0.792 \\
\hline \multirow[t]{3}{*}{ IMP } & IMP1 & $\lambda 61$ & 0.728 & 0.053 & 13.678 & 0.000 & 0.624 & 0.833 & 0.774 \\
\hline & IMP2 & $\lambda 62$ & 0.728 & 0.056 & 12.999 & 0.000 & 0.618 & 0.838 & 0.745 \\
\hline & IMP3 & $\lambda 63$ & 0.577 & 0.054 & 10.599 & 0.000 & 0.470 & 0.683 & 0.637 \\
\hline \multirow[t]{2}{*}{ REL } & REL1 & $\lambda 71$ & 0.900 & 0.062 & 14.604 & 0.000 & 0.780 & 1.021 & 0.824 \\
\hline & REL2 & $\lambda 72$ & 0.857 & 0.059 & 14.522 & 0.000 & 0.742 & 0.973 & 0.820 \\
\hline \multirow[t]{4}{*}{ ACC } & $\mathrm{ACC} 1$ & $\lambda 81$ & 0.796 & 0.061 & 13.145 & 0.000 & 0.677 & 0.915 & 0.749 \\
\hline & ACC2 & $\lambda 82$ & 0.926 & 0.058 & 16.070 & 0.000 & 0.813 & 1.039 & 0.859 \\
\hline & ACC3 & $\lambda 83$ & 0.772 & 0.061 & 12.744 & 0.000 & 0.653 & 0.891 & 0.733 \\
\hline & ACC4 & $\lambda 84$ & 0.770 & 0.059 & 13.047 & 0.000 & 0.654 & 0.886 & 0.745 \\
\hline
\end{tabular}

Note. $\mathrm{DIR}=$ direct experience, $\mathrm{KNO}=$ knowledge, $\mathrm{EXT}=$ extremity $/$ intensity, $\mathrm{AFC}=$ affective-cognitive consistency, CER = certainty, $\mathrm{IMP}=$ importance, $\mathrm{REL}=$ interest in relevant information, $\mathrm{ACC}=$ accessibility. 
The detailed questionnaire is available at https:// doi.org/10.5281/zenodo.5606479 (accessed on 9 September 2021). The 8 dimensions are the features that compose the score of a construct, namely attitude.

The entire scale's construct validity to be used in this questionnaire was generated from the confirmatory factor analysis (CFA), with model fit indices presented in Table 13 (A related figure can be found at https:/ / doi.org/10.5281/zenodo.5606479 (accessed on 9 September 2021), in worksheet CFA-Instrument Validation).

This present study used at least any two of the following criteria, CFI $>0.80, \mathrm{TLI}>0.80$, SRMR $<0.08$, GFI $>0.90$, and RMSEA $<0.08$ to indicate a fit CFA model. The use of the cut-off scores was based on the literature review of Akkus [57] (pp. 712-713), that "It is accepted model has a good fit since CFI $\geq 0.8 \ldots$ If RMSEA is $\leq 0.08$ it indicates good fit with reasonable errors ... SRMR value below $\leq 0.08$ indicates good fit ... AGFI, GFI and CFI values should be $\geq 0.80 \ldots$ TLI $\geq 0.85$ indicates good fit and $>0.8$ mediocre fit".

Table 13. Model fit indices of each variable $(N=244)$.

\begin{tabular}{|c|c|c|c|c|c|c|}
\hline Variable & $\begin{array}{l}\text { Comparative } \\
\text { Fit Index } \\
\text { (CFI) }\end{array}$ & $\begin{array}{l}\text { Tucker- } \\
\text { Lewis Index } \\
\text { (TLI) }\end{array}$ & $\begin{array}{c}\text { Standardized Root } \\
\text { Mean Square } \\
\text { Residual (SRMR) }\end{array}$ & $\begin{array}{l}\text { Bentler-Bonett } \\
\text { Normed Fit } \\
\text { Index (NFI) }\end{array}$ & $\begin{array}{l}\text { Goodness } \\
\text { of Fit Index } \\
\text { (GFI) }\end{array}$ & $\begin{array}{l}\text { Root Mean Square } \\
\text { Error of } \\
\text { Approximation } \\
\text { (RMSEA) }\end{array}$ \\
\hline $\begin{array}{l}\text { Attitude towards water } \\
\text { purification technology }\end{array}$ & 0.860 & 0.832 & 0.069 & 0.797 & 0.806 & 0.083 \\
\hline \multicolumn{7}{|l|}{ Personality traits } \\
\hline Conscientiousness & 0.869 & 0.826 & 0.068 & 0.823 & 0.913 & 0.094 \\
\hline Neuroticism & 0.898 & 0.857 & 0.059 & 0.868 & 0.925 & 0.106 \\
\hline Agreeableness & 0.792 & 0.723 & 0.070 & 0.726 & 0.930 & 0.090 \\
\hline Extraversion & 0.871 & 0.820 & 0.065 & 0.830 & 0.929 & 0.099 \\
\hline Openness & 0.714 & 0.633 & 0.107 & 0.657 & 0.902 & 0.078 \\
\hline \multicolumn{7}{|l|}{ Cultural value orientation } \\
\hline Uncertainty avoidance & 0.949 & 0.898 & 0.044 & 0.936 & 0.965 & 0.121 \\
\hline Power distance & 0.974 & 0.948 & 0.035 & 0.958 & 0.981 & 0.080 \\
\hline Collectivism & 0.908 & 0.846 & 0.063 & 0.884 & 0.955 & 0.115 \\
\hline Masculinity & 0.979 & 0.936 & 0.034 & 0.971 & 0.987 & 0.099 \\
\hline Long-term orientation & 0.992 & 0.976 & 0.024 & 0.982 & 0.993 & 0.054 \\
\hline
\end{tabular}

\section{Results}

The descriptive statistics of each variable involved in this study are presented in Table 14. Meanwhile, the correlations between variables are presented in Table 15.

Simple linear regressions showed that the personality trait (the potential mediator), conscientiousness $\left(R^{2}=0.051 ; F(1,243)=12.902 ; p=0.000\right)$, neuroticism $\left(R^{2}=0.020 ; F(1\right.$, $243)=4.822 ; p=0.029)$, agreeableness $\left(R^{2}=0.047 ; F(1,243)=12.041 ; p=0.000\right)$, extraversion $\left(R^{2}=0.024 ; F(1,243)=5.906 ; p=0.016\right)$, and openness $\left(R^{2}=0.068 ; F(1,243)=17.714 ;\right.$ $p=0.000$ ), can directly predict attitude toward water purification technology (see Table 16). 
Table 14. Descriptive statistics $(N=244)$.

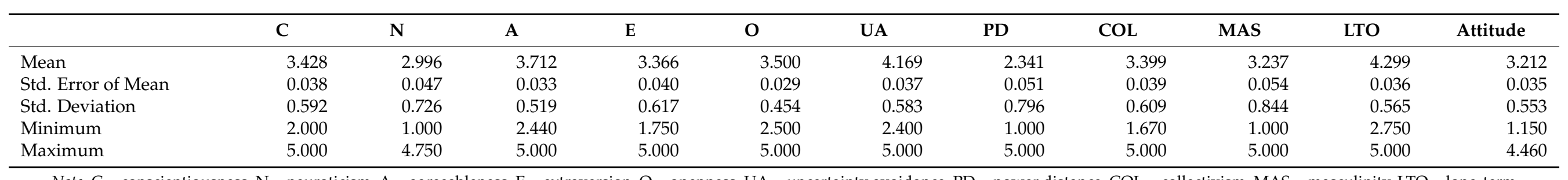

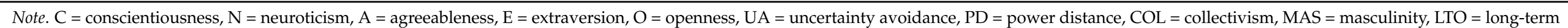
orientation, Attitude = attitude towards water purification technology.

Table 15. Pearson correlation matrix $(N=244)$.

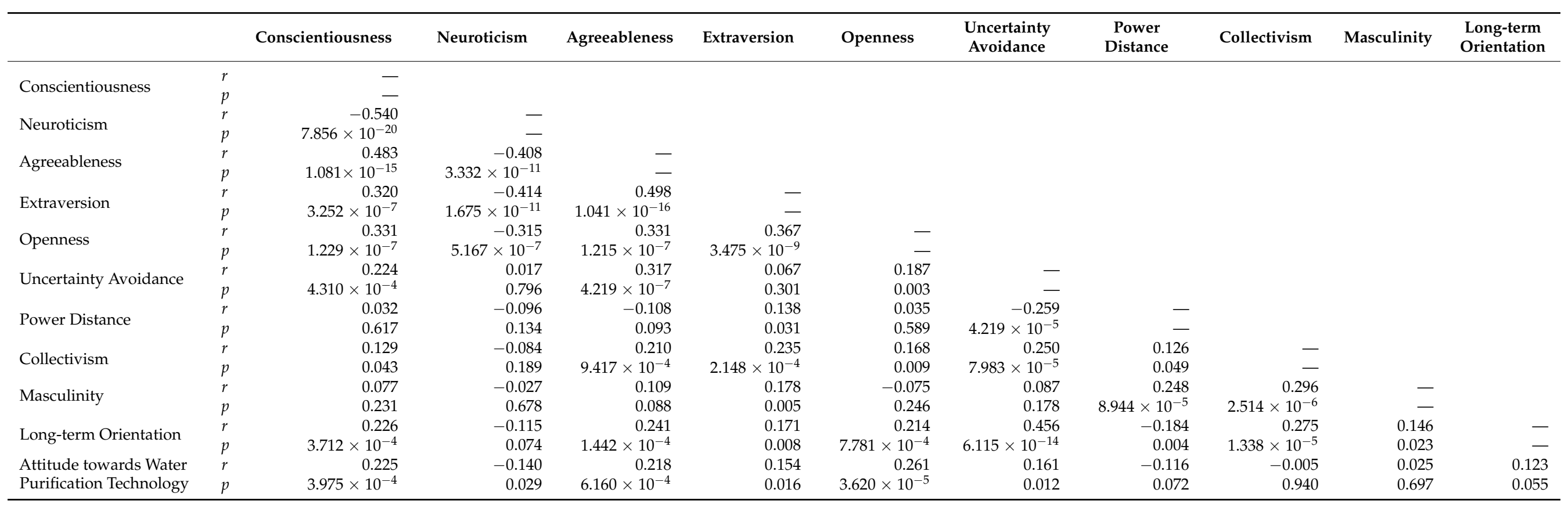


Table 16. Simple linear regressions predicting attitude towards water purification technology $(N=244)$.

\begin{tabular}{|c|c|c|c|c|c|c|c|}
\hline \multirow[b]{2}{*}{ Personality Trait } & \multirow[b]{2}{*}{ Unstandardized } & \multirow[b]{2}{*}{ Standard Error } & \multirow[b]{2}{*}{ Standardized } & \multirow[b]{2}{*}{$t$} & \multirow[b]{2}{*}{$p$} & \multicolumn{2}{|c|}{$95 \% \mathrm{CI}$} \\
\hline & & & & & & Lower & Upper \\
\hline Conscientiousness & 0.210 & 0.059 & 0.225 & 3.592 & $3.975 \times 10^{-4}$ & 0.095 & 0.326 \\
\hline Neuroticism & -0.106 & 0.048 & -0.140 & -2.196 & 0.029 & -0.202 & -0.011 \\
\hline Agreeableness & 0.232 & 0.067 & 0.218 & 3.470 & $6.160 \times 10^{-4}$ & 0.100 & 0.364 \\
\hline Extraversion & 0.138 & 0.057 & 0.154 & 2.430 & 0.016 & 0.026 & 0.250 \\
\hline Openness & 0.268 & 0.064 & 0.261 & 4.209 & $3.620 \times 10^{-5}$ & 0.142 & 0.393 \\
\hline
\end{tabular}

The results of the mediation analysis show that the personality trait conscientiousness is functional as a mediator $(p=0.018, p<0.05)$ of the relationship between the cultural value orientation uncertainty avoidance and attitude towards water purification technology (see Figure 1 and Tables 17-19). Thus, the first hypothesis (H1) of this present study is supported by empirical data.

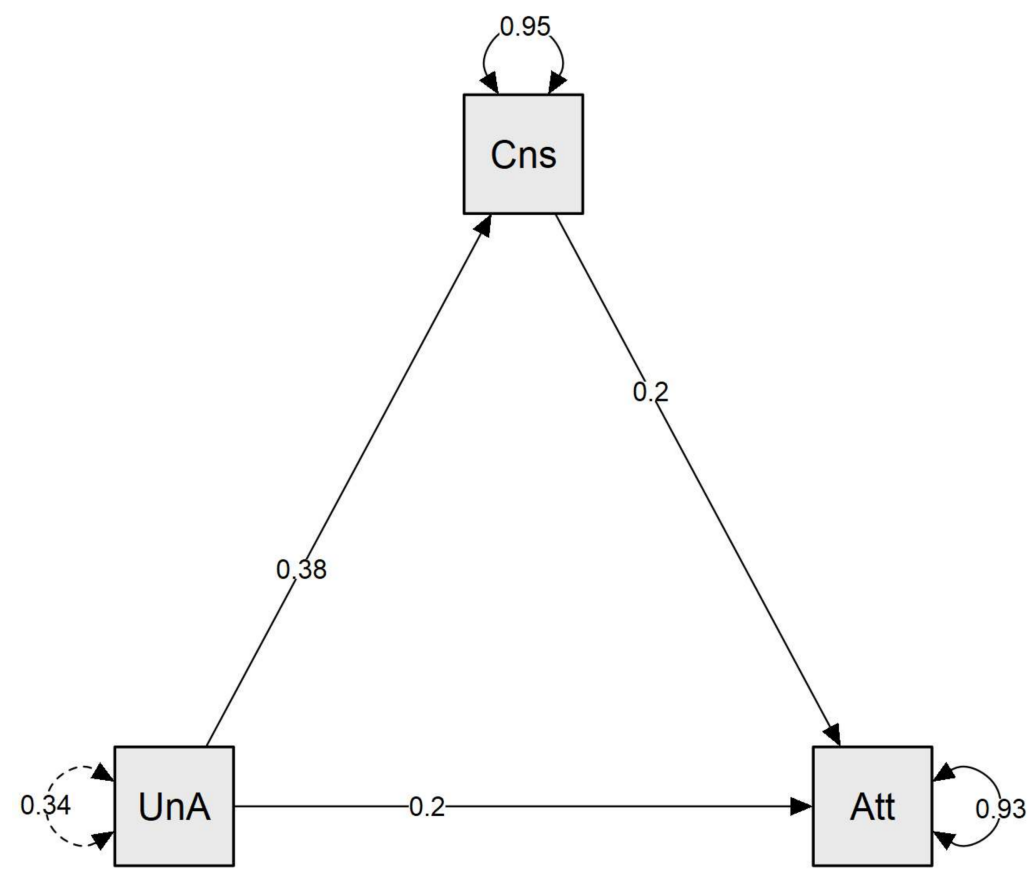

Figure 1. Mediation analysis predicting attitude towards water purification technology (Att) with uncertainty avoidance $(\mathrm{UnA})$ as the predictor and conscientiousness $(\mathrm{Cns})$ as the moderator $(N=244)$.

Table 17. Direct effect of uncertainty avoidance on attitude towards water purification technology $(N=244)$.

\begin{tabular}{lllrrrrrr}
\hline & & & & & \multicolumn{2}{c}{$95 \%$ Confidence Interval } \\
\hline & & & Estimate & Std. Error & $z$ & $p$ & Lower & Upper \\
\hline Uncertainty Avoidance & $\rightarrow$ & Attitude & 0.200 & 0.109 & 1.831 & 0.067 & -0.014 & 0.413 \\
\hline
\end{tabular}

Note. Delta method standard errors, normal theory confidence intervals. 
Table 18. Indirect effect of uncertainty avoidance on attitude towards water purification technology through conscientiousness $(N=244)$.

\begin{tabular}{|c|c|c|c|c|c|c|c|c|}
\hline & & & \multicolumn{6}{|c|}{ 95\% Confidence Interval } \\
\hline & & & Estimate & Std. Error & $z$ & $p$ & Lower & Upper \\
\hline Uncertainty Avoidance & $\rightarrow$ Conscientiousness $\rightarrow$ & Attitude & 0.076 & 0.032 & 2.358 & 0.018 & 0.013 & 0.140 \\
\hline
\end{tabular}

Note. Delta method standard errors, normal theory confidence intervals.

Table 19. Total effect of uncertainty avoidance on attitude towards water purification technology through conscientiousness $(N=244)$.

\begin{tabular}{cccccccccc}
\hline & & & & & & & 95\% Confidence Interval \\
\hline & & & Estimate & Std. Error & $z$ & $p$ & Lower & Upper \\
\hline Uncertainty Avoidance & $\rightarrow$ & Attitude & 0.276 & 0.108 & 2.546 & 0.011 & 0.064 & 0.488 \\
\hline & \multicolumn{2}{c}{ Note. Delta method standard errors, normal theory confidence intervals. } & &
\end{tabular}

Note. Delta method standard errors, normal theory confidence intervals.

The results of the mediation analysis show that the personality trait neuroticism is not functional as a mediator $(p=0.200, p>0.05)$ of the relationship between the cultural value orientation power distance and attitude towards water purification technology (see Figure 2 and Tables 20-22). Thus, the second hypothesis (H2) from this present study is not supported by empirical data.

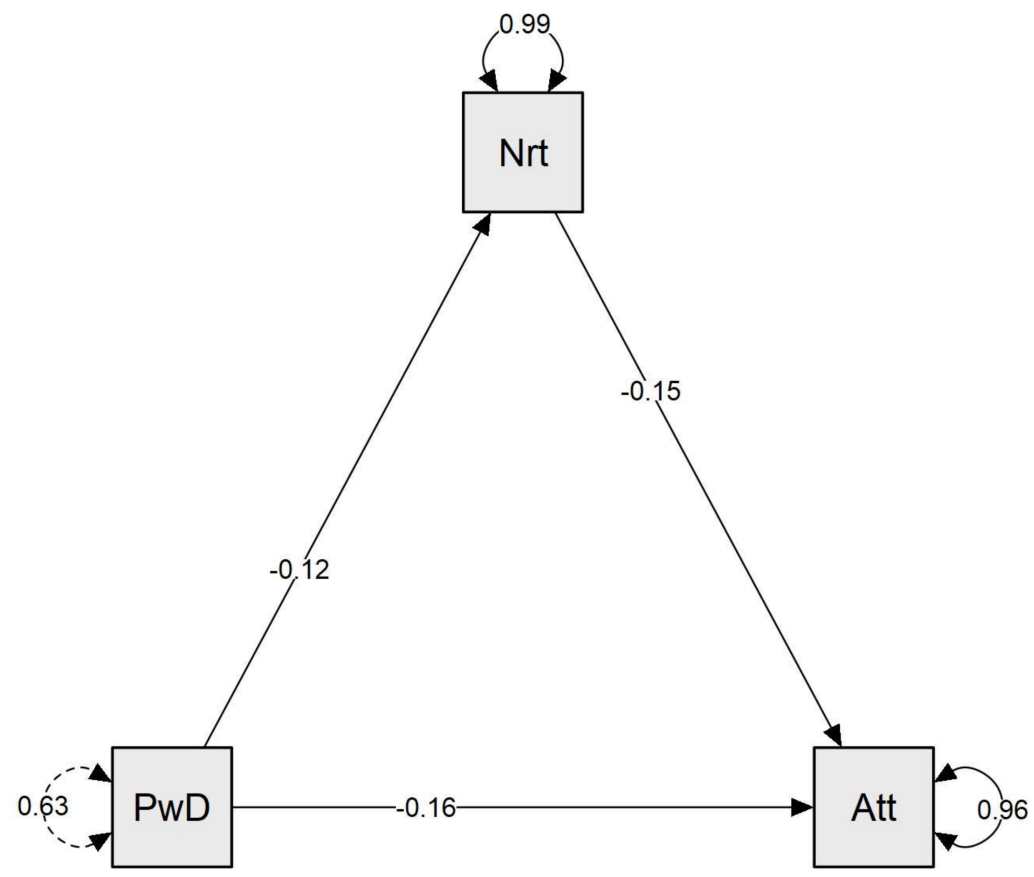

Figure 2. Mediation analysis predicting attitude towards water purification technology (Att) with power distance $(\mathrm{PwD})$ as the predictor and neuroticism $(\mathrm{Nrt})$ as the moderator $(N=244)$.

Table 20. Direct effect of power distance on attitude towards water purification technology $(N=244)$.

\begin{tabular}{llcrrrrrrr}
\hline & \multicolumn{1}{c}{} & & & \multicolumn{3}{c}{ 95\% Confidence Interval } \\
\hline & & & Estimate & Std. Error & $z$ & $p$ & Lower & Upper \\
\hline Power Distance & $\rightarrow$ & Attitude & -0.164 & 0.079 & -2.063 & 0.039 & -0.319 & -0.008 \\
\hline
\end{tabular}


Table 21. Indirect effect of power distance on attitude towards water purification technology through neuroticism $(N=244)$.

\begin{tabular}{rrrrrrrrrr}
\hline & & & & & & \multicolumn{2}{c}{ 95\% Confidence Interval } \\
\hline & & & Estimate & Std. Error & $z$ & $p$ & Lower & Upper \\
\hline Power Distance & $\rightarrow$ & Neuroticism $\rightarrow$ & Attitude & 0.018 & 0.014 & 1.281 & 0.200 & -0.010 & 0.047 \\
\hline
\end{tabular}

Note. Delta method standard errors, normal theory confidence intervals.

Table 22. Total effect of power distance on attitude towards water purification technology through neuroticism $(N=244)$.

\begin{tabular}{llcrrrrrr}
\hline & \multicolumn{1}{c}{} & & & \multicolumn{3}{c}{ 95\% Confidence Interval } \\
\hline & & Estimate & Std. Error & $z$ & $p$ & Lower & Upper \\
\hline Power Distance & $\rightarrow$ & Attitude & -0.145 & 0.080 & -1.817 & 0.069 & -0.302 & 0.011 \\
\hline
\end{tabular}

Note. Delta method standard errors, normal theory confidence intervals.

The results of the mediation analysis show that the personality trait agreeableness is functional as a mediator $(p=0.014, p<0.05)$ of the relationship between the cultural value orientation collectivism and attitude towards water purification technology (see Figure 3 and Tables 23-25). Thus, the third hypothesis (H3) from this present study is supported by empirical data.

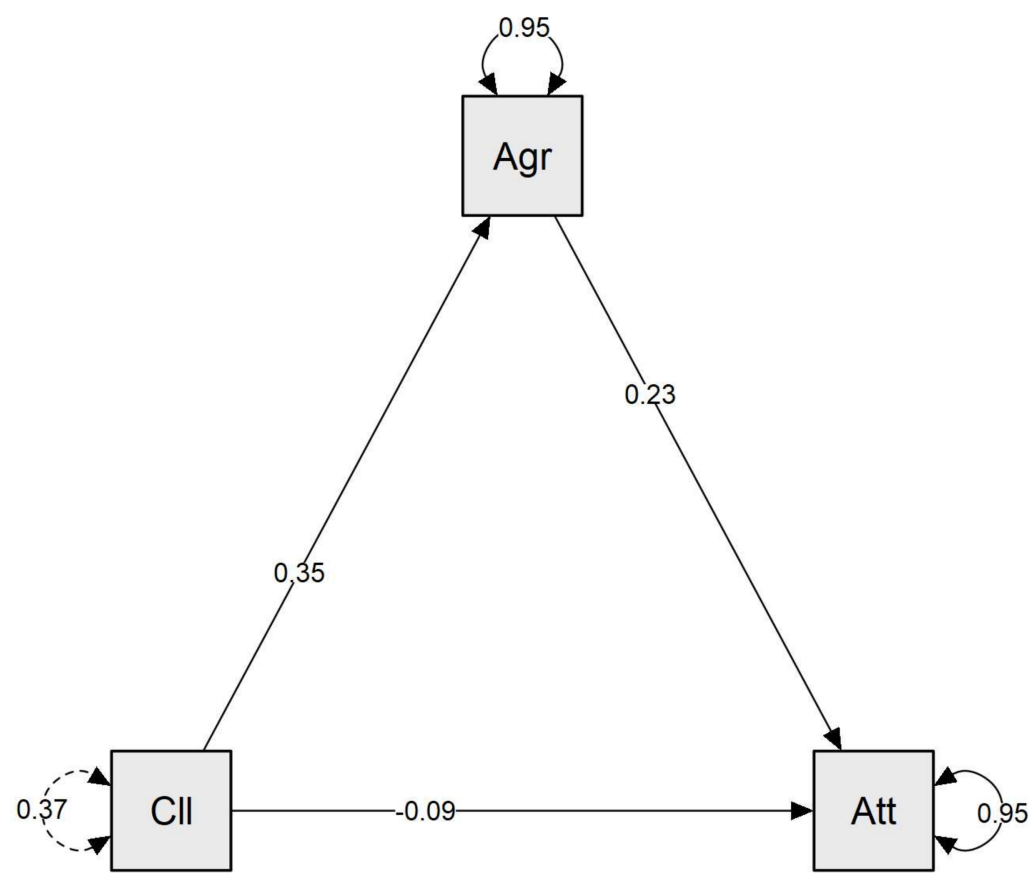

Figure 3. Mediation analysis predicting attitude towards water purification technology (Att) with collectivism (Cll) as the predictor and agreeableness (Agr) as the moderator $(N=244)$.

Table 23. Direct effect of collectivism on attitude towards water purification technology $(N=244)$.

\begin{tabular}{ccccccccc}
\hline & \multicolumn{1}{c}{} & & & \multicolumn{2}{c}{ 95\% Confidence Interval } \\
\hline & & & Estimate & Std. Error & $z$ & $p$ & Lower & Upper \\
\hline Collectivism & $\rightarrow$ & Attitude & -0.087 & 0.105 & -0.831 & 0.406 & -0.293 & 0.118 \\
\hline & Note. Delta method standard errors, normal theory confidence intervals. & &
\end{tabular}


Table 24. Indirect effect of collectivism on attitude towards water purification technology through agreeableness $(N=244)$.

\begin{tabular}{lrrrrrrrr}
\hline & & & & & \multicolumn{2}{c}{ 95\% Confidence Interval } \\
\hline & & & Estimate & Std. Error & $z$ & $p$ & Lower & Upper \\
\hline Collectivism $\rightarrow$ & Agreeableness $\rightarrow$ & Attitude & 0.079 & 0.032 & 2.453 & 0.014 & 0.016 & 0.142 \\
\hline
\end{tabular}

Note. Delta method standard errors, normal theory confidence intervals.

Table 25. Total effect of collectivism on attitude towards water purification technology through agreeableness $(N=244)$.

\begin{tabular}{llcrrrrrrr}
\hline & \multicolumn{1}{c}{} & & & \multicolumn{3}{c}{ 95\% Confidence Interval } \\
\hline & & Estimate & Std. Error & $z$ & $p$ & Lower & Upper \\
\hline Collectivism & $\rightarrow$ & Attitude & -0.008 & 0.105 & -0.076 & 0.939 & -0.214 & 0.198 \\
\hline
\end{tabular}

Note. Delta method standard errors, normal theory confidence intervals.

The results of the mediation analysis show that the personality trait extraversion is not functional as a mediator $(p=0.067, p>0.05)$ of the relationship between the cultural value orientation masculinity and attitude towards water purification technology (see Figure 4 and Tables 26-28). Thus, the fourth hypothesis (H4) from this present study is not supported by empirical data.

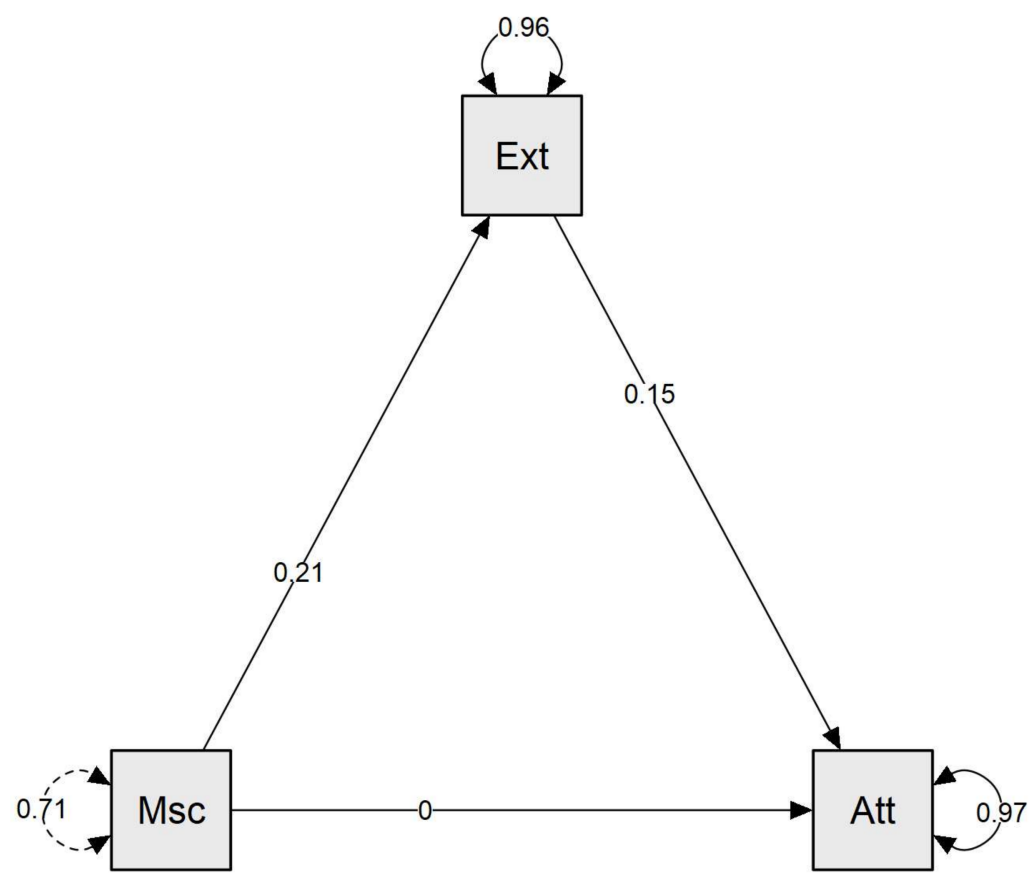

Figure 4. Mediation analysis predicting attitude towards water purification technology (Att) with masculinity (Msc) as the predictor and extraversion (Ext) as the moderator $(N=244)$.

Table 26. Direct effect of masculinity on attitude towards water purification technology $(N=244)$.

\begin{tabular}{ccccccccc}
\hline & & & & & \multicolumn{2}{c}{ 95\% Confidence Interval } \\
\hline & & & Estimate & Std. Error & $z$ & $p$ & Lower & Upper \\
\hline Masculinity & $\rightarrow$ & Attitude & -0.003 & 0.076 & -0.040 & 0.968 & -0.152 & 0.146 \\
\hline & Note. Delta method standard errors, normal theory confidence intervals. & &
\end{tabular}


Table 27. Indirect effect of masculinity on attitude towards water purification technology through extraversion $(N=244)$.

\begin{tabular}{llrrrrrrrr}
\hline & & & & & \multicolumn{3}{c}{$95 \%$ Confidence Interval } \\
\hline & & & Estimate & Std. Error & $z$ & $p$ & Lower & Upper \\
\hline Masculinity $\rightarrow$ & Extraversion & $\rightarrow$ & Attitude & 0.033 & 0.018 & 1.835 & 0.067 & -0.002 & 0.068 \\
\hline
\end{tabular}

Note. Delta method standard errors, normal theory confidence intervals.

Table 28. Total effect of masculinity on attitude towards water purification technology through extraversion $(N=244)$.

\begin{tabular}{rlrrrrrrrr}
\hline & \multicolumn{1}{c}{} & & & \multicolumn{3}{c}{ 95\% Confidence Interval } \\
\hline & & & Estimate & Std. Error & $z$ & \multicolumn{1}{c}{$\boldsymbol{p}$} & Lower & Upper \\
\hline Masculinity & $\rightarrow$ & Attitude & 0.030 & 0.076 & 0.391 & 0.696 & -0.119 & 0.178 \\
\hline
\end{tabular}

Note. Delta method standard errors, normal theory confidence intervals.

The results of the mediation analysis show that the personality trait openness is functional as a mediator $(p=0.010, p<0.05)$ of the relationship between the cultural value orientation long-term orientation and attitude towards water purification technology (see Figure 5 and Tables 29-31). Thus, the fifth hypothesis (H5) from this present study is supported by empirical data.

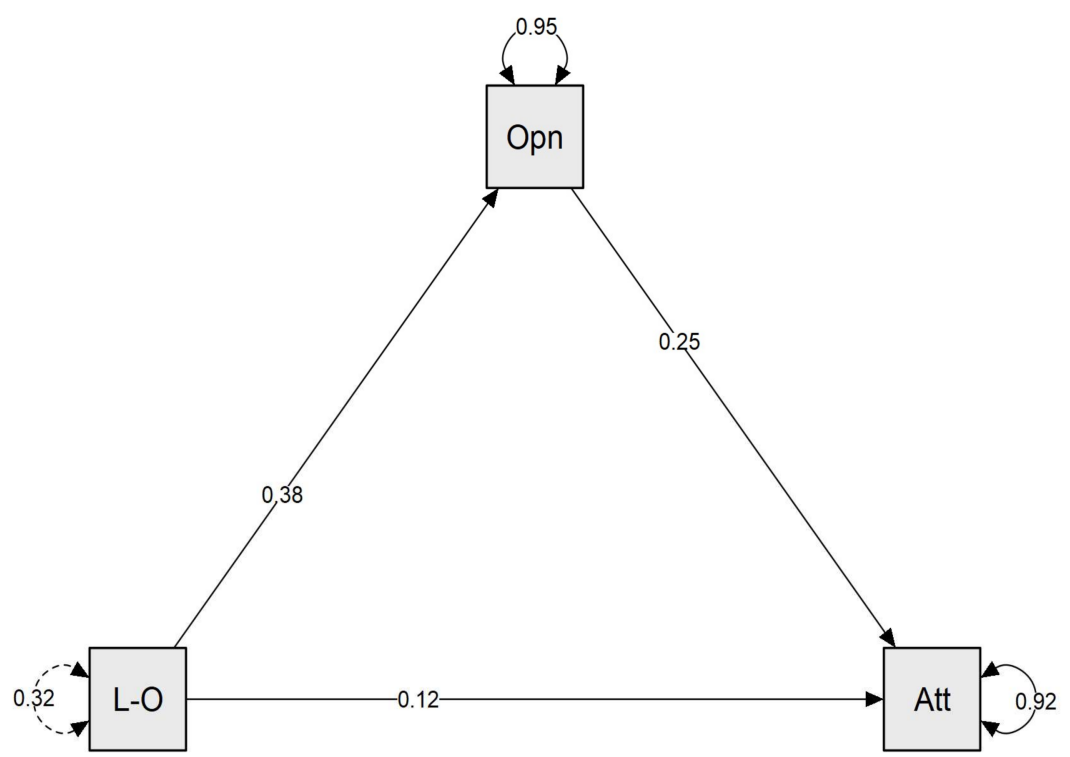

Figure 5. Mediation analysis predicting attitude towards water purification technology (Att) with long-term orientation $(\mathrm{L}-\mathrm{O})$ as the predictor and openness $(\mathrm{Opn})$ as the moderator $(N=244)$.

Table 29. Direct effect of long-term orientation on attitude towards water purification technology $(N=244)$.

\begin{tabular}{lllrrrrrr}
\hline & & & & & \multicolumn{3}{c}{$95 \%$ Confidence Interval } \\
\hline & & & Estimate & Std. Error & $z$ & $p$ & Lower & Upper \\
\hline Long-term Orientation & $\rightarrow$ & Attitude & 0.125 & 0.112 & 1.117 & 0.264 & -0.094 & 0.343 \\
\hline
\end{tabular}

Note. Delta method standard errors, normal theory confidence intervals. 
Table 30. Indirect effect of long-term orientation on attitude towards water purification technology through openness $(N=244)$.

95\% Confidence Interval

\begin{tabular}{ccrrrrrrr}
\hline & & Estimate & Std. Error & $z$ & $p$ & Lower & Upper \\
\hline Long-term Orientation & $\rightarrow$ Openness $\rightarrow$ Attitude & 0.093 & 0.036 & 2.570 & 0.010 & 0.022 & 0.164 \\
\hline \multicolumn{1}{c}{ Note. Delta method standard errors, normal theory confidence intervals. }
\end{tabular}

Table 31. Total effect of long-term orientation on attitude towards water purification technology through openness $(N=244)$.

\begin{tabular}{lllrrrrrr}
\hline & & & & & \multicolumn{2}{c}{$95 \%$ Confidence Interval } \\
\hline & & & Estimate & Std. Error & $z$ & \multicolumn{1}{c}{$p$} & Lower & Upper \\
\hline Long-term Orientation & $\rightarrow$ & Attitude & 0.218 & 0.112 & 1.937 & 0.053 & -0.003 & 0.438 \\
\hline
\end{tabular}

Note. Delta method standard errors, normal theory confidence intervals.

\section{Discussion}

This present study found that three out of five (or $60 \%$ ) hypotheses proposed by the authors, being Hypothesis 1, Hypothesis 3, and Hypothesis 5, were supported by empirical data. The three hypotheses were that (1) conscientiousness mediates the predictive relationship between uncertainty avoidance and attitude toward water purification technology, (2) agreeableness mediates the predictive relationship between collectivism and the attitude, and (3) openness mediates the predictive relationship between long-term orientation and the attitude. Testing of these three hypotheses also showed no direct predictions / effect of cultural value orientation toward the attitude (see Tables 17, 23 and 29; $p>0.05$ ).

This present study might be the first to investigate multiple variable combinations of cultural orientation and personality that can predict attitudes toward disruptive change (in this regard, water purification technology).

Confirmation of the majority of the hypotheses empirically indicates that the effect of culture on attitudes toward disruptive changes tends to be mediated by personality traits. Aside from the explanations presented in the Introduction, there is correspondence with prior similar research although in different variable configurations and contexts.

A study by Sahertian et al. [58] found that the "Pela Gondong" culture (brotherly relationship between villages) in Maluku, Indonesia, affects personality first, before eventually influencing employee performance. A literature review by Muttaqin [59] (p. 8) stated that culture directly influences personality, "The concept of cultural orientation is often used to understand the self as an individual in different cultures ... Different cultural orientations may cause different self-construal which comprises thought, feeling, and action related to the self as a response to perceived cultural orientation". When in fact, it is personality (as instituted in this present study) that provides a coherent sense of self [60]. Furthermore, in the current era of gamification, the analogy of culture's influence toward personality is interesting to examine and can be found in Oishi et al. [61] (p. 686, 689), as follows:

"Rohner's (1984) [62] metaphor comparing culture to a game (with various rules) and people to its players clearly illustrates this point. Players can pick from different strategies and options, and sometimes even violate or modify the rules if they think they can get away with it ... Currently, most personality researchers see personality variables (e.g., selfand other- ascribed traits, self-concept and identity, well-being, goals) as reflecting, at least in part, distal and proximal cultural processes, in that cultural norms and values influence the meaning, function, and expected levels of these psychological attributes (McAdams and Pals, 2006) [21]".

In the context of attitudes toward new technology, cultural value orientation not only plays a role in the pre-adoption phase of technology but, rather, cultural value orientation can predict post-adoption perceptions of technology. This is termed the "culture-technology fit model", as substantiated by Lee et al. [63] in East Asian countries (Hong Kong, Korea, Taiwan). This present study contributes toward existing theoretical models on attitudes 
toward new technology by adding evidence on how the effect of cultural orientation is mediated by personality traits.

In addition, this present study also found that Hypothesis 2 and Hypothesis 4 were not supported by empirical data. The absence of a mediating effect will be explained by utilizing Kenny's [64] mediation methodology.

Neuroticism did not function as a mediator in the predictive relationship between power distance cultural orientation and attitude toward water purification technology. When examining Pearson's intervariable correlation (Table 15), it shows that (1) power distance and neuroticism are uncorrelated $(r=-0.096, p=0.134)$ and (2) neuroticism is negatively correlated with attitude $(r=-0.140, p=0.029)$, but (3) power distance is uncorrelated with attitude $(r=-0.116, p=0.072)$.

Based on these results, neuroticism's lack of function as a mediator may be contributed to by the correlational absence between power distance and neuroticism. This may be due to the possibility that when the hypotheses were formulated, the authors did not deliberate as to how high power distance attributes may result in different emotionalities depending on the person's position. Indeed, in the authors' review in the Introduction, it was stated that undemocratic situations as an implication of power distance may result in high neuroticism. This may only be applicable for individuals in lower positions (impoverished, less powerful, more marginalized). What was missed or left out is the possibility that undemocratic, inequal, or even autocratic, paternalistic situations (as an inherent issue from high power distance) may potentially be enjoyed by individuals in higher positions (richer, more powerful, more elitist in terms of social status). As it is enjoyable, then high power distance in individuals with higher positions may yield low rather than high neuroticism.

Explanations on those possibilities correspond to a statement by Hareli et al. [65] (p. 378), "These findings suggest that observers hold a naïve theory that closely matches Keltner et al.'s (2003) [66] model and associate high power (as well as status and social dominance) with approach-related emotions such as anger and pride, and low power/status/ dominance with inhibition-related emotions such as sadness and fear". With the existence of ambiguity on the emotional consequences of such power distance (approach and inhibition related), then it is reasonable that there were uncertain correlational directions between power distance and neuroticism, thus power distance did not demonstrate its predictive power toward water purification technology attitudes through neuroticism.

Extraversion did not function as a mediator in the predictive relationship between masculinity and cultural orientation and attitude toward water purification technology. When examining Pearson's intervariable correlation (Table 15), it shows that (1) masculinity is positively correlated with extraversion $(r=0.178, p=0.005)$ and (2) extraversion is positively correlated with attitude $(r=0.154, p=0.016)$, but (3) masculinity is not correlated with attitude $(r=0.025, p=0.697)$.

Based on these results, extraversion's lack of function as a mediator may be contributed to by the correlational absence between masculinity and attitude towards water purification technology as one of the innovations to overcome the dangers of the safe water crisis. Handoyo [67] also discovered this correlational absence on a national level, whereby cultural orientation masculinity is unassociated with national innovative capacity $(r=-0.026, p>0.05)$. Unfortunately, no explanation was provided on this finding. Meanwhile, Özbilen [68] found that, also on a national level, masculinity does not influence new technology adoption on firm levels. It was explained that this may be due to the absence of "intense local competition" in organizations in various countries to use new technology. Therefore, the masculine attributes (i.e., competitiveness) that an organization possesses were not facilitated directing to the higher adoption of new technology. Still, on the national level, a study by Apriyantopo and Aprianingsih [69] in Asian countries also had similar findings. They explained that the Asian countries being studied (majority of developing countries) were more oriented toward social values (feminine quality) rather than material reward and competitiveness-as possessed by developed countries. 
Although both studies $[68,69]$ were conducted on national levels, however, the findings and explanations in both studies inspire the explanations in this study's findings. This present study was conducted in Indonesian samples whereby "Indonesia is less masculine than some other Asian countries such as Japan, China, and India. In Indonesia, status and visible symbols of success are important but it is not always material gain that brings motivation" [70] (para. 9). If a new technology, such as water purification technology, is assumed to be a part of the "material gain that brings motivation", then it is evident how masculinity is unimportant, irrelevant, and insignificant to form attitudes toward it.

The significant role of the trio-traits or three facets of personality (conscientiousness, agreeableness, and openness) in predicting attitudes toward water purification technology can be compared with the results of other studies that also yielded similar findings in numerous contexts. For instance, Luengo Kanacri et al.'s [71] (p. 710) study found that "changes in Agreeableness, Conscientiousness, and Openness were related to change in prosocial behaviors". In the Introduction, we agreed that the use of water purification technology supports environmental sustainability, and this behavior is part of prosocial behavior as it will save both the earth and its inhabitants from the clean water crisis.

Aside from that, a study by Shappie et al. [72] (p. 4) found that "Conscientiousness, Agreeableness, and Openness were the only factors that were significantly associated with self-reported cybersecurity behaviors". Although their study was in a cyber context-which differs from this present study—the "security behavior" element of their research can be generalized to the findings in this study. In a society that prioritizes mutual cooperation ("gotong royong") such as in Indonesia [73], such behavior can be realized by securing the mutually inhabited ecology or enhancing environmental security. Eventually, these three traits were found to be "consistent with holding and living out a principled ethical ideology" [74] (p. 39), which is a quality compatible with sustainability-advocating behaviors by using technological facilitation.

\section{Conclusions, Implications, and Limitations}

This study concludes that attitude toward water purification technology (as part of disruptive changes in the technology area), that supports environmental sustainability, can be predicted by cultural value orientation, not directly but rather indirectly as mediated by personality traits. The configuration of variables that can predict the attitudes is as follows: (1) uncertainty avoidance and conscientiousness, (2) collectivism and agreeableness, and (3) long-term orientation and openness. Nonetheless, the lack of predictive power of two variable configurations, being (1) power distance and neuroticism and (2) masculinity and extraversion, were reviewed and elaborated on in the Discussion above.

The managerial implication of this study is that, when an organization, whether small or large scale or even nation state, is willing to participate in safeguarding water sustainability — by endorsing and advocating the use of water purification technology - then integrating considerations as well as culture and personality is an urgent matter. This is due to the fact that environmental knowledge and reasoning is insufficient in instigating change for people's maladaptive behavior toward the environment, hence it is important to determine which cultural orientation and/or personal factor has the greatest influence in bringing about change, including shifting to use technology that can support the environment.

Generally, personality traits are known to be resilient or resistant toward change. Despite this, empirical studies in the last seven years [75-77] have asserted the malleability of personality traits, particularly when individuals who possess such traits intend to change them. This is also termed the pathway of volitional change, which relies on a person's strong determination to change. Nonetheless, there are other paths, such as experience pathways or social habituation, as suggested by Hudson and Fraley [77] (p. 2), as follows:

“There is evidence that people's experiences-and the social roles that they occupy, in particular-may idiosyncratically sculpt their personality traits ... Theoretically, these personality trait changes occur for at least two reasons. First, 
different social roles (e.g., employee, romantic partner) require and reinforce specific patterns of thoughts, feelings, and behaviors ... A second reason social roles might catalyze trait change is that social roles influence how people conceptualize and construe their social identities".

Concerning social role pathways for changes in personality traits, Baranski et al. [75] further explained:

"The resounding implication emerging from this body of work-that the adoption of certain social roles/occurrence of major life events corresponds with certain trait changes-underscores our collective capacity to adapt effectively to novel events and/or stimuli".

Based on the assumption above, there is a sense of optimism to enhance attitudes toward disruptive changes by eliciting or enhancing conscientiousness, agreeableness, and openness levels within a person by reorienting them toward their cultural values. This can be achieved by assigning certain social roles to a person or a group of persons whom we aim to enhance attitudes toward water purification technology. As put forward by Sunstein [78], social roles present social meaning that determines the issues appreciated by a person-conceptualized by this study as cultural value orientation.

In addition, if a community or organization leader wants to modify behavior of others who previously did not want to use water purification technology, then the leader can hold communicative events with those by considering their cultural values [79]. More concretely, Falkheimer and Heide [80] provided four suggestions on how to organize communicative events that can forge one's personality, namely (1) audience orientation-concentrating sense-making, (2) proactive and interactive approach-focusing discussion, (3) communityfocused approach-focusing a long-term view, and (4) ethnicity-based approach to intercultural communication. These four tips are useful to be applied to increase positive attitudes towards water purification technology by utilizing knowledge about one's cultural values.

This present study investigating attitudes towards water purification can form a case study for other attitudes relating to technological change. However, the applications of this study must be performed ethically and with caution. This is because cultural value orientation has different impacts across various aspects of life in all individuals. For example, manipulating social roles to enhance uncertainty avoidance (so that it yields high conscientiousness, as based on this study) may eventually increase positive attitudes toward water purification technology. Nevertheless, it must be noted that increasing uncertainty avoidance may be unfavorable or unwanted by a person due to its negative impact on other areas of life.

This study has three notable limitations that introduce a certain degree of bias into the study. Firstly, study participants that were recruited through convenience sampling and limited to a metropolitan society may be less representative to illustrate the psychological dynamics of attitudes toward water purification technology in the Indonesian population. Future studies may expand the geographical scope of participants' origins and enhance the quality of sampling by using various probability sampling methods (such as simple or stratified random sampling). Secondly, the data retrieval in this study for all variables was conducted at one point in time, in what is known as a cross-sectional study. The classic problem of this data collection method is the common method variance [81], which presents the possibility of an inflated correlation from this study's results. Future research is recommended to replicate this study extracting data on these three variables in separate time points, or more longitudinal in quality. Thirdly, this study has yet to include cultural orientation in the form of indulgence (vs. restraint). This is because the cultural orientation scale used in this study is the adoption of Yoo et al.'s [18] work that only validated measurements of cultural orientation on the individual level within five dimensions. Indulgence- the degree to which people attempt to regulate their urges and impulses as a result of their upbringing-is a relatively new dimension, coined as the "sixth dimension" as added by Hofstede et al. [19]. Efforts for instrument adaptation of the 
indulgence variable from the country to individual level has not been undertaken until recently by Heydari et al. [82]. Future studies are expected to integrate the indulgence dimension with the relevant personality traits as a prospective predictor of attitude toward water purification technology. Lastly, accounting for other pro-environment factors, such as connectedness to nature, environmental concerns, or including an ecological behavioral scale, may be necessary to generate a more detailed illustration of the link between personality, culture, and preservation behaviors that will further lead to more substantial implications for social change.

Author Contributions: Conceptualization, J.A. and I.S.; methodology, J.A. and I.S.; software, J.A. and H.L.H.S.W.; validation, J.A. and I.S.; formal analysis, J.A. and I.S.; investigation, J.A. and I.S.; resources, J.A., R.H.M., H.L.H.S.W. and Y.S.R.; data curation, J.A. and I.S.; writing-original draft preparation, J.A. and I.S.; writing-review and editing, J.A., I.S., R.H.M., H.L.H.S.W. and Y.S.R.; visualization, J.A. and H.L.H.S.W.; supervision, J.A.; project administration, J.A. and R.H.M.; funding acquisition, J.A., R.H.M., H.L.H.S.W. and Y.S.R. All authors have read and agreed to the published version of the manuscript.

Funding: This research was funded by Directorate of Resources, Directorate General of Higher Education, The Indonesian Ministry of Education, Culture, Research, and Technology, in accordance with the Research Contract for Fiscal Year 2021, Number: 163/E4.1/AK.04.PT/2021, 3481/LL3/KR/2021, 12 July 2021, with the research title, "Exploring the Contribution of Personality and Societal Cultural Orientation in Explaining Attitudes Toward Disruptive Changes".

Institutional Review Board Statement: The study was conducted according to the guidelines of the Declaration of Helsinki. Specific ethical review and approval were waived for this study, due to its low and negligible character of risk, i.e., no more than minimal burden and no more than inconvenience, as well as noninvasive, nonclinical, and nonexperimental study being performed, of which this exemption is in accordance with Table 1 in Scott, A.M.; Kolstoe, S.; Ploem, M.C.C.; Hammatt, Z.; Glasziou, P. Exempting low-risk health and medical research from ethics reviews: comparing Australia, the United Kingdom, the United States and the Netherlands. Health Res. Policy Syst. 2020, 18, 11, https: / / doi.org/10.1186/s12961-019-0520-4 (accessed on 1 June 2021) [83]. The research protocol has been ethically and substantively approved to be conducted by the Indonesian Ministry of Education, Culture, Research and Technology as well as Bina Nusantara University, Indonesia, based on Decision Letter Number: 1867/E4/AK.04/2021 as well as Agreement/Contract Letter Number: 163/E4.1/AK.04.PT/2021, 3481/LL3/KR/2021, and 042/VR.RTT/VI/2021.

Informed Consent Statement: Informed consent was obtained from all subjects involved in the study.

Data Availability Statement: The complete Indonesian and English questionnaire as well as the entire data of this present study are available online and can be accessed through the following link: https:/ / doi.org/10.5281/zenodo.5606479 (accessed on 9 September 2021).

Acknowledgments: We would like to thank Stephane Bressan from the Department of Computer Science of the School of Computing at the National University of Singapore for inspiring us to care about the water situation, especially in developing countries.

Conflicts of Interest: The authors declare no conflict of interest.

\section{References}

1. UN Water. Water Scarcity. United Nations. 2021. Available online: https://www.unwater.org/water-facts/scarcity/ (accessed on 9 September 2021).

2. Burek, P.; Satoh, Y.; Fischer, G.; Kahil, T.; Jimenez, L.; Scherzer, A.; Tramberend, S.; Wada, Y.; Eisner, S.; Flörke, M.; et al. Water Futures and Solution-Fast Track Initiative (Final Report); International Institute for Applied Systems Analysis (IIASA): Luxemburg, 2016; p. 113. Available online: http:/ / pure.iiasa.ac.at/id/eprint/13008/ (accessed on 9 September 2021).

3. Lisbona, N. Finding Answers to the World's Drinking Water Crisis. BBC News, 2 August 2021. Available online: https: //www.bbc.com/news/business-57847654 (accessed on 9 September 2021).

4. Rahman, M.S.; Islam, M. Sustainability of Current Water Purification Technologies. In Sustainable Water Purification; Scrivener Publishing LLC: Beverly, MA, USA, 2020; pp. 59-122. [CrossRef]

5. Ahmad, A.; Azam, T. Water Purification Technologies. In Bottled and Packaged Water: The Science of Beverages; Grumezescu, A.M., Holban, A.M., Eds.; Woodhead Publishing: Sawston, UK, 2019; Volume 4, pp. 83-120. [CrossRef] 
6. Voutchkov, N. Disruptive Innovation in the Water Sector. The Solutions Journal. 17 May 2020. Available online: https:// thesolutionsjournal.com/2020/05/14/disruptive-innovation-water-sector/ (accessed on 9 September 2021).

7. Howard, G.S. When psychology looks like a "soft" science, it's for good reasonp. J. Theor. Philos. Psychol. 1993, 13, 42-47. [CrossRef]

8. Kubala, J. Purified vs. Distilled vs. Regular Water: What's the Difference? HealthLine, 1 March 2018. Available online: https://www.healthline.com/nutrition/purified-vs-distilled-vs-regular-water (accessed on 9 September 2021).

9. Fielding, K.S.; Dolnicar, S.; Schultz, T. Public acceptance of recycled water. Int. J. Water Resour. Dev. 2018, 35, 551-586. [CrossRef]

10. Lee, J.; Kim, K.; Shin, H.; Hwang, J. Acceptance factors of appropriate technology: Case of water purification systems in Binh Dinh, Vietnam. Sustainability 2018, 10, 2255. [CrossRef]

11. Harmon, D.; Gauvain, M.; Reisz, Z.; Arthur, I.; Story, S.D. Preference for tap, bottled, and recycled water: Relations to PTC taste sensitivity and personality. Appetite 2018, 121, 119-128. [CrossRef] [PubMed]

12. Marks, J.; Martin, B.; Zadoroznyj, M. How Australians order acceptance of recycled water. J. Sociol. 2008, 44, 83-99. [CrossRef]

13. Mykota, D.B. Culture and Personality. In The Wiley Encyclopedia of Personality and Individual Differences: Personality Processes and Individual Differences; John Wiley \& Sons, Inc.: Hoboken, NJ, USA, 2020; pp. 95-99. [CrossRef]

14. Leong, F.T.L.; Serafica, F.C. Career development of Asian Americans: A research area in need of a good theory. In Career Development and Vocational Behavior of Racial and Ethnic Minorities; Leong, F.T.L., Ed.; Lawrence Erlbaum: Hillsdale, NJ, USA, 2014; pp. 67-102.

15. Holland, J.L. Making Vocational Choices: A Theory of Vocational Personalities and Work Environments, 2nd ed.; Prentice-Hall: Englewood Cliffs, NJ, USA, 1985.

16. Hofstede, G.; McCrae, R.R. Personality and culture revisited: Linking traits and dimensions of culture. Cross-Cult. Res. 2004, 38, 52-88. [CrossRef]

17. Miller, J.G. Cultural psychology: Implications for basic psychological theory. Psychol. Sci. 1999, 10, 85-91. [CrossRef]

18. Yoo, B.; Donthu, N.; Lenartowicz, T. Measuring Hofstede's five dimensions of cultural values at the individual level: Development and validation of CVSCALE. J. Int. Consum. Mark. 2012, 23, 193-210.

19. Hofstede, G.; Hofstede, G.J.; Minkov, M. Cultures and Organizations: Software of the Mind, 3rd ed.; McGraw-Hill: London, UK, 2010.

20. Chirkov, V.; Ryan, R.M.; Kim, Y.; Kaplan, U. Differentiating autonomy from individualism and independence: A self-determination theory perspective on internalization of cultural orientations and well-being. J. Pers. Soc. Psychol. 2003, 84, 97-110. [CrossRef] [PubMed]

21. McAdams, D.P.; Pals, J.L. A new Big Five: Fundamental principles for an integrative science of personality. Am. Psychol. 2006, 61, 204-217. [CrossRef] [PubMed]

22. John, O.P.; Naumann, L.P.; Soto, C.J. Paradigm shift to the integrative Big-Five trait taxonomy: History, measurement, and conceptual issues. In Handbook of Personality: Theory and Research; John, O.P., Robins, R.W., Pervin, L.A., Eds.; Guilford Press: New York, NY, USA, 2008.

23. Brenner, F.S.; Ortner, T.M.; Fay, D. Asynchronous video interviewing as a new technology in personnel selection: The applicant's point of view. Front. Psychol. 2016, 7, 863. [CrossRef] [PubMed]

24. Wuertz, T. Personality Traits Associated with Environmental Concern. Ph.D. Thesis, Walden University, Minneapolis, MN, USA, 2015. Available online: https:/ / scholarworks.waldenu.edu/cgi/viewcontent.cgi?article=1307\&context=dissertations (accessed on 9 September 2021).

25. Ribeiro, J.D.A.; Veiga, R.T.; Higuchi, A.K. Personality traits and sustainable consumption. Rev. Bras. Mark. 2016, 15, 297-313. [CrossRef]

26. Hofstede, G. The GLOBE debate: Back to relevance. J. Int. Bus. Stud. 2010, 41, 1339-1346. [CrossRef]

27. Gründl, J.; Aichholzer, J. Support for the populist radical right: Between uncertainty avoidance and risky choice. Polit. Psychol. 2020, 41, 641-659. [CrossRef]

28. Berenbaum, H.; Bredemeier, K.; Thompson, R.J. Intolerance of uncertainty: Exploring its dimensionality and associations with need for cognitive closure, psychopathology, and personality. J. Anxiety Disord. 2008, 22, 117-125. [CrossRef] [PubMed]

29. Punnoose, A.C. Determinants of intention to use elearning based on the Technology Acceptance Model. J. Inf. Technol. Educ. Res. 2012, 11, 301-337. [CrossRef]

30. Wester, J.; Timpano, K.R.; Çek, D.; Broad, K. The psychology of recycled water: Factors predicting disgust and willingness to use. Water Resour. Res. 2016, 52, 3212-3226. [CrossRef]

31. Mitte, K. Trait-disgust vs. fear of contamination and the judgmental bias of contamination concerns. J. Behav. Ther. Exp. Psychiatry 2008, 39, 577-586. [CrossRef]

32. Migliore, L.A. Relation between big five personality traits and Hofstede's cultural dimensions. Cross Cult. Manag. Int. J. 2011, 18, 38-54. [CrossRef]

33. He, J.; Li, D. What the Leader Said Made Me Lose Control: Leaders' Aggressive Humor and Employees' Workplace Deviance Behaviors. In 5th Annual International Conference on Social Science and Contemporary Humanity Development (SSCHD 2019); Atlantis Press: Dordrecht, The Netherlands, 2019; pp. 249-255. [CrossRef]

34. Oshio, T.; Urakawa, K. The association between perceived income inequality and subjective well-being: Evidence from a social survey in Japan. Soc. Indic. Res. 2013, 116, 755-770. [CrossRef]

35. Fatke, M. Personality traits and political ideology: A first global assessment. Polit. Psychol. 2016, 38, 881-899. [CrossRef] 
36. Özbek, V.; Alnıaçık, Ü.; Koc, F.; Akkılıç, M.E.; Kaş, E. The impact of personality on technology acceptance: A study on smart phone users. Procedia Soc. Behav. Sci. 2014, 150, 541-551. [CrossRef]

37. Maican, C.I.; Cazan, A.-M.; Lixandroiu, R.C.; Dovleac, L. A study on academic staff personality and technology acceptance: The case of communication and collaboration applications. Comput. Educ. 2018, 128, 113-131. [CrossRef]

38. Hirsh, J.B. Environmental sustainability and national personality. J. Environ. Psychol. 2014, 38, 233-240. [CrossRef]

39. Burton, L.; DelVecchio, E.; Germani, A.; Mazzeschi, C. Individualism/collectivism and personality in Italian and American Groups. Curr. Psychol. 2019, 40, 29-34. [CrossRef]

40. Realo, A.; Allik, J.; Vadi, M. The hierarchical structure of collectivism. J. Res. Pers. 1997, 31, 93-116. [CrossRef]

41. Javalagi, A.; Newman, D.A. Cross-Cultural Collectivism supports Extraversion and Agreeableness Leadership Advantage. In Academy of Management Proceedings; Academy of Management: Briarcliff Manor, NY, USA, 2021; Volume 2021. [CrossRef]

42. Triandis, H.C.; Suh, E.M. Cultural influences on personality. Annu. Rev. Psychol. 2002, 53, 133-160. [CrossRef] [PubMed]

43. Behrenbruch, K.; Söllner, M.; Leimeister, J.M.; Schmidt, L. Understanding diversity-The impact of personality on technology acceptance. In IFIP Conference on Human-Computer Interaction; Springer: Berlin/Heidelberg, Germany, 2013; pp. 306-313. [CrossRef]

44. Svendsen, G.B.; Johnsen, J.-A.K.; Almås-Sørensen, L.; Vittersø, J. Personality and technology acceptance: The influence of personality factors on the core constructs of the Technology Acceptance Model. Behav. Inf. Technol. 2013, 32, 323-334. [CrossRef]

45. Di Fabio, A.; Rosen, M.A. Accounting for individual differences in connectedness to nature: Personality and gender differences. Sustainability 2019, 11, 1693. [CrossRef]

46. Clapton, A. How Water Filtering Helps Save Water-And the Planet. Blue E Green Tomorrow, 16 January 2019 . Available online: https://blueandgreentomorrow.com/environment/how-water-filtering-helps-save-water-and-planet/ (accessed on 9 September 2021).

47. Zheng, L.; Zheng, Y. The relationship of masculinity and femininity to the Big Five personality dimensions among a Chinese sample. Soc. Behav. Pers. Int. J. 2011, 39, 445-450. [CrossRef]

48. Marušić, I.; Bratko, D. Relations of masculinity and femininity with personality dimensions of the Five-Factor Model. Sex Roles 1998, 38, 29-44. [CrossRef]

49. Althuizen, N. Using structural technology acceptance models to segment intended users of a new technology: Propositions and an empirical illustration. Inf. Syst. J. 2017, 28, 879-904. [CrossRef]

50. Poškus, M. What works for whom? Investigating adolescents' pro-environmental behaviors. Sustainability 2020, $12,7313$. [CrossRef]

51. Zotzmann, Y.; van der Linden, D.; Wyrwa, K. The relation between country differences, cultural values, personality dimensions, and error orientation: An approach across three continents-Asia, Europe, and North America. Saf. Sci. 2019, 120, $185-193$. [CrossRef]

52. Krishnan, S. Personality and espoused cultural differences in technostress creators. Comput. Hum. Behav. 2017, 66, 154-167. [CrossRef]

53. Rüdian, S.; Vladova, G.; Kazimizade, G.; Gundlach, J.; Pinkwart, N. Predicting culture and personality in online courses. In Proceedings of the first International Workshop on Supporting Lifelong Learning co-located with the 20th International Conference on Artificial Intelligence (AIED 2019), Chicago, IL, USA, 29 June 2019; pp. 8-15. Available online: http:/ / ceur-ws.org/ Vol-2395/paper2.pdf (accessed on 9 September 2021).

54. Ramdhani, N. Adaptasi bahasa dan budaya dari skala kepribadian Big Five [Language and cultural adaptation of the Big Five personality scale]. J. Psikol. 2012, 39, 189-207. [CrossRef]

55. Schermelleh-Engel, K. Re: For Analysis in SPSS, Should We Use "Average" of All Scales or "Sums"? 2015. Available online: https://www.researchgate.net/post/For_analysis_in_SPSS_should_we_use_average_of_all_scales_or_sums/555ef11f630 7d96a0f8b456a/citation/download (accessed on 9 September 2021).

56. Krosnick, J.A.; Boninger, D.S.; Chuang, Y.C.; Berent, M.K.; Carnot, C.G. Attitude strength: One construct or many related constructs? J. Pers. Soc. Psychol. 1993, 65, 1132-1151. [CrossRef]

57. Akkus, A. Developing a scale to measure students' attitudes toward science. Int. J. Assess. Tools Educ. 2019, 6, 706-720. [CrossRef]

58. Sahertian, O.L.; Setiawan, M.; Sunaryo, S. Culture and employee performance: The mediating role of personality and commitment. Manag. Sci. Lett. 2020, 1567-1574. [CrossRef]

59. Muttaqin, D. The role of cultural orientation in adolescent identity formation: Self-construal as a mediator. Makara Hum. Behav. Stud. Asia 2020, 24, 7-16. [CrossRef]

60. Scalabrini, A.; Mucci, C.; Northoff, G. Is our self related to personality? A neuropsychodynamic model. Front. Hum. Neurosci. 2018, 12, 346. [CrossRef] [PubMed]

61. Oishi, S.; Kushlev, K.; Benet-Martinez, V. Culture and personality: Current directions. In Handbook of Personality: Theory and Research, 4th ed.; John, O.P., Robins, R.W., Eds.; Guilford Press: New York, NY, USA, 2021; pp. 686-704.

62. Rohner, R.P. Toward a conception of culture for cross-cultural psychology. J. Cross-Cult. Psychol. 1984, 15, 111-138. [CrossRef]

63. Lee, I.; Choi, B.; Kim, J.; Hong, S.-J. Culture-technology fit: Effects of cultural characteristics on the post-adoption beliefs of mobile Internet users. Int. J. Electron. Commer. 2007, 11, 11-51. [CrossRef]

64. Kenny, D.A. Mediation. 2021. Available online: http:// davidakenny.net/cm/mediate.htm (accessed on 9 September 2021). 
65. Hareli, S.; Shomrat, N.; Hess, U. Emotional versus neutral expressions and perceptions of social dominance and submissiveness. Emotion 2009, 9, 378-384. [CrossRef] [PubMed]

66. Keltner, D.; Gruenfeld, D.H.; Anderson, C. Power, approach, and inhibition. Psychol. Rev. 2003, 110, 265-284. [CrossRef] [PubMed]

67. Handoyo, S. The role of national culture in national innovative capacity. Asian J. Technol. Manag. 2018, 11, 137-149. [CrossRef]

68. Özbilen, P. The impact of natural culture on new technology adoption by firms: A country level analysis. Int. J. Innov. Manag. Technol. 2017, 8, 299-305. [CrossRef]

69. Apriyantopo, W.; Aprianingsih, A. Information communication and technology (ICT) adoption in Asian Countries: An empirical evidence of economic and socio-cultural factors. Binus Bus. Rev. 2020, 11, 175-186. [CrossRef]

70. Hofstede Insights. What about Indonesia? 2021. Available online: https://www.hofstede-insights.com/country/indonesia/ (accessed on 9 September 2021).

71. Kanacri, B.P.L.; Pastorelli, C.; Eisenberg, N.; Zuffiano, A.; Castellani, V.; Caprara, G.V. Trajectories of prosocial behavior from adolescence to early adulthood: Associations with personality change. J. Adolesc. 2014, 37, 701-713. [CrossRef] [PubMed]

72. Shappie, A.T.; Dawson, C.A.; Debb, S.M. Personality as a predictor of cybersecurity behavior. Psychol. Popul. Media Cult. 2020, 9 , 475-480. [CrossRef]

73. Slikkerveer, L.J. Gotong Royong: An indigenous institution of communality and mutual assistance in Indonesia. In Integrated Community-Managed Development; Springer: Cham, Switzerland, 2019; pp. 307-320. [CrossRef]

74. McFerran, B.; Aquino, K.; Duffy, M. How personality and moral identity relate to individuals' ethical ideology. Bus. Ethics $Q$. 2010, 20, 35-56. [CrossRef]

75. Baranski, E.N.; Morse, P.J.; Dunlop, W.L. Lay conceptions of volitional personality change: From strategies pursued to stories told. J. Pers. 2016, 85, 285-299. [CrossRef] [PubMed]

76. Hudson, N.; Roberts, B.W. Goals to change personality traits: Concurrent links between personality traits, daily behavior, and goals to change oneself. J. Res. Pers. 2014, 53, 68-83. [CrossRef]

77. Hudson, N.W.; Fraley, R.C. Volitional personality trait change: Can people choose to change their personality traits? J. Pers. Soc. Psychol. 2015, 109, 490-507. [CrossRef] [PubMed]

78. Sunstein, C.R. Social norms and social roles. Columbia Law Rev. 1996, 96, 903. [CrossRef]

79. Wang, L.; Bruce, C.; Hughes, H. Sociocultural theories and their application in information literacy research and education. Aust. Acad. Res. Libr. 2011, 42, 296-308. [CrossRef]

80. Falkheimer, J.; Heide, M. Multicultural crisis communication: Towards a social constructionist perspective. J. Contingencies Crisis Manag. 2006, 14, 180-189. [CrossRef]

81. Juneman, J. Common method variance \& bias dalam penelitian psikologis [Common method variance \& bias in psychological research]. J. Pengukuran Psikol. dan Pendidik. Indones. 2013, 2, 364-381.

82. Heydari, A.; Laroche, M.; Paulin, M.; Richard, M.-O. Hofstede's individual-level indulgence dimension: Scale development and validation. J. Retail. Consum. Serv. 2021, 62, 102640. [CrossRef]

83. Scott, A.M.; Kolstoe, S.; Ploem, M.C.C.; Hammatt, Z.; Glasziou, P. Exempting low-risk health and medical research from ethics reviews: Comparing Australia, the United Kingdom, the United States and the Netherlands. Health Res. Policy Syst. 2020, 18, 11. [CrossRef] [PubMed] 